\title{
Changes in midlife death rates across racial and ethnic groups in the United States: systematic analysis of vital statistics
}

\author{
Steven H Woolf, ${ }^{1}$ Derek A Chapman, ${ }^{1}$ Jeanine M Buchanich, ${ }^{2}$ Kendra J Bobby, ${ }^{2}$ \\ Emily B Zimmerman, ${ }^{1}$ Sarah M Blackburn ${ }^{1}$
}

${ }^{1}$ Center on Society and Health,

Virginia Commonwealth

University, 830 East Main

Street, Richmond, VA 23298-

0212, USA; Department of

Family Medicine and Population

Health, Virginia Commonwealth

University, VA, USA

${ }^{2}$ Department of Biostatistics,

Graduate School of Public

Health, University of Pittsburgh,

Pittsburgh, PA, USA

Correspondence to: SH Woolf

steven.woolf@vcuhealth.org

(or @shwoolf on Twitter)

Additional material is published online only. To view please visit the journal online.

Cite this as: BMJ 2018;362:k3096 http://dx.doi.org/10.1136/bmj.k3096

Accepted: 11 July 2018

\section{ABSTRACT}

OBJECTIVE

To systematically compare midlife mortality patterns in the United States across racial and ethnic groups during 1999-2016, documenting causes of death and their relative contribution to excess deaths.

DESIGN

Trend analysis of US vital statistics among racial and ethnic groups.

SETTING

United States, 1999-2016.

POPULATION

US adults aged 25-64 years (midlife).

\section{MAIN OUTCOME MEASURES}

Absolute changes in mortality measured as average year-to-year change during 1999-2016 and 2012-16; excess deaths attributable to increasing mortality; and relative changes in mortality measured as relative difference between mortality in 1999 versus 2016 and the nadir year versus 2016, and the slope of modeled mortality trends for 1999-2016 and for intervals between joinpoints.

RESULTS

During 1999-2016, all cause mortality in midlife increased not only among non-Hispanic $(\mathrm{NH})$ whites but also among NH American Indians and Alaskan Natives. Although all cause mortality initially decreased among NH blacks, Hispanics, and NH Asians and Pacific Islanders, this trend ended in 2009-11. Drug overdoses were the leading cause of increased mortality in midlife in each population, but mortality also increased for alcohol related conditions, suicides, and organ diseases involving multiple body

\section{WHAT IS ALREADY KNOWN ON THIS TOPIC}

Mortality rates among whites aged 25-64 years (midlife) have increased since the 1990s, a trend attributed primarily to drug overdoses, alcohol related liver disease, and suicides

Prior studies suggested that this trend was not occurring among non-Hispanic blacks and Hispanics, the largest minority populations in the US

\section{WHAT THIS STUDY ADDS}

Midlife mortality rates in the US are increasing not only among non-Hispanic whites but also among Hispanics and non-Hispanic American Indians and Alaskan Natives, blacks, and Asians and Pacific Islanders

Although drug overdoses, alcohol related liver disease, and suicides played a major role, mortality rates also increased across a broad spectrum of diseases involving multiple body systems

The wide range of affected conditions points to the need to examine systemic causes of declining health in the US systems. Although midlife mortality among NH whites increased across a multitude of conditions, a similar trend affected non-white populations. Absolute (yearto-year) increases in midlife mortality among nonwhite populationsoften matched or exceeded those of $\mathrm{NH}$ whites, especially in 2012-16, when the rate of increase intensified for many causes of death. During 1999-2016, NH American Indians and Alaskan Natives experienced large increases in midlife mortality from 12 causes, not only drug overdoses (411.4\%) but also hypertensive diseases (269.3\%), liver cancer (115.1\%), viral hepatitis (112.1\%), and diseases of the nervous system (99.8\%). NH blacks experienced increased midlife mortality from 17 causes, including drug overdoses (149.6\%), homicides (21.4\%), hypertensive diseases (15.5\%), obesity (120.7\%), and liver cancer (49.5\%). NH blacks also experienced retrogression: after a period of stable or declining midlife mortality early in 1999-2016, death rates increased for alcohol related liver disease, chronic lower respiratory tract disease, suicides, diabetes, and pancreatic cancer. Among Hispanics, midlife mortality increased across 12 causes, including drug overdoses (80.0\%), hypertensive diseases (40.6\%), liver cancer (41.8\%), suicides (21.9\%), obesity (106.6\%), and metabolic disorders (60.0\%). Retrogression also occurred in this population; after a period of declining mortality, death rates increased for alcohol related liver disease, mental and behavioral disorders involving psychoactive substances, and homicides. NH Asians and Pacific Islanders were least affected by this trend but also experienced increases in midlife mortality from drug overdoses (300.6\%), alcohol related liver disease (62.9\%), hypertensive diseases (28.3\%), and brain cancer (56.6\%). The suicide rate in this group increased by $29.7 \%$ after 2001. The relative increase in US midlife mortality differed by sex and geography. For example, the relative increase in fatal drug overdoses was greater among women than among men. Although the relative increase in midlife mortality was generally greater in non-metropolitan (ie, rural) areas, the relative increase in drug overdoses among $\mathrm{NH}$ whites and Hispanics was greatest in suburban fringe areas of large cities, and among $\mathrm{NH}$ blacks was greatest in small cities.

\section{CONCLUSIONS}

Mortality in midlife in the US has increased across racial-ethnic populations for a variety of conditions, especially in recent years, offsetting years of progress in lowering mortality rates. This reversal carries added consequences for racial groups with high baseline mortality rates, such as for $\mathrm{NH}$ blacks and NH American Indians and Alaskan Natives. That death 
rates are increasing throughout the US population for dozens of conditions signals a systemic cause and warrants prompt action by policy makers to tackle the factors responsible for declining health in the US.

\section{Introduction}

Life expectancy in the United States has been decreasing since 2014. ${ }^{12}$ This development, after years of lengthening life expectancy, has been attributed to increasing mortality rates among whites-mainly those aged 25-64 years (midlife). ${ }^{3-11}$ Explanations for this trend, which began in the 1990s, typically cite fatal drug overdoses, alcohol related liver disease, and suicides ${ }^{6-8}$-referred to by some as "deaths of despair." 1213 Reports have identified other contributors to increasing midlife mortality (eg, heart and lung disease, stroke, Alzheimer's disease, diabetes), but findings have been inconsistent..$^{4-6} 11$ Few investigators have used a systematic approach to examine causes of death comprehensively.

Mortality patterns in non-white populations are even less clear. Investigators report profound increases in mortality among American Indians and Alaskan Natives of all ages, but they claim the reverse-that mortality rates are decreasing-among blacks, Hispanics, and Asians and Pacific Islanders. ${ }^{4} 581114$ Data across multiple reports suggest, however, that cause specific mortality rates have indeed been increasing among black and Hispanic populations. ${ }^{4581415-18}$ Except for recent coverage of the spread of the opioid epidemic to minority populations, ${ }^{19} 20$ the possibility that midlife mortality might be increasing across racial and ethnic groups, reversing years of progress, has received little public attention.

Previous studies may have missed these reversals in mortality because of the methods used to measure changes in rates, which typically center on comparing current mortality rates with those of a reference year; authors report rates as unchanged if the difference between the two values is not statistically significant. These two point comparisons easily overlook important fluctuations in mortality that occur during intervening years. Trend lines in publications ${ }^{1417}$ show mortality rates for some conditions decreasing after 1999, reaching a nadir, and then reversing direction and increasing.

The only way to expose these patterns is to study year-to-year mortality trends. The most current data should be included, given recent surges in mortality rates, but we are aware of no studies on this topic that have examined vital statistics comprehensively beyond 2015. Mortality trends should also be compared by sex, given the evidence that women and men are differentially impacted, ${ }^{5} 15212223$ and by geographic settings. Scientific ${ }^{1121}$ and lay ${ }^{24-26}$ publications in the US often portray increasing mortality rates in midlife, particularly among the white population, as a rural phenomenon. Whether this is true for populations of color is unclear.

We examined diverse racial groups (non-Hispanic American Indians and Alaskan Natives, Asians and Pacific Islanders, blacks, and whites) and the Hispanic population and compared results by sex and geographic setting; used a systematic, comprehensive approach to detail causes of death; included year-toyear trend analyses over 17 years rather than only relying on two fixed point comparisons; and extended the analysis through 2016.

\section{Methods}

We examined age adjusted mortality rates based on the 2000 US standard population for 1999-2016 using the Underlying Cause of Death Detailed Mortality database in the Center for Disease Control and Prevention's Wideranging Online Data for Epidemiologic Research (CDC WONDER) platform. ${ }^{27}$ The agency's methods for age adjustment are described elsewhere. ${ }^{28}$ In our analysis we focused on mortality in midlife, defined as deaths at ages 25-64 years (most reports of increasing mortality have studied age groups within these bounds ${ }^{3-11}$ ). Per federal regulations, ${ }^{28}$ we considered mortality rates for any cell (ie, specific cause of death, racial-ethnic group, and year) to be unreliable and therefore did not report them here if they were based on 10-20 deaths (those based on fewer than 10 deaths are suppressed and not publicly available). Causes of death were coded using ICD-10 (international classification of diseases, 10th revision). ${ }^{29}$ To avoid inconsistencies in coding with the ninth revision, we excluded deaths before 1999. We obtained mortality rates for all cause mortality, the 113 ICD-10 selected causes of death, and other causes of death with statistically significant increases in mortality during 1999-2016.

Causes of death were divided into 20 broad categories: infectious and parasitic diseases (ICD-10 codes A00-B99); neoplasms (C00-D48); diseases of the blood and immune mechanism (D50-D89); endocrine, nutritional, and metabolic diseases (E00-E88); mental and behavioral disorders (F01-F99); diseases of the nervous system (G00-G98), eye and adnexa (Ho0-H57), ear and mastoid process (H60-H93), circulatory system (I00-I99), respiratory system (J00-J98), digestive system (K00-K92), skin and subcutaneous tissue (L00-L98), musculoskeletal system and connective tissue (M00-M99), and genitourinary system (N00-N98); pregnancy, childbirth, and the puerperium (000-099); conditions originating in the perinatal period (P00-P96); congenital malformations, deformations, and chromosomal abnormalities (Q00-Q99); symptoms, signs, and abnormal clinical and laboratory findings, not elsewhere classified (R00-R99); codes for special purposes (U00-U99); and external causes (V01-Y89). We broadly classified these as external causes-a category that includes drug overdoses, suicides, and other unintentional and intentional injuries-and as organ diseases. Deaths due to alcohol related causes, as calculated by the National Center for Health Statistics, were also examined.

During 1999-2016 many causes of death exhibited retrogression-a period of stable or declining mortality rates followed by a statistically significant increase in rates. We therefore studied relative increases in 
mortality rates as two point comparisons, between 1999 and 2016 and between the nadir year and 2016. Non-overlapping 95\% confidence intervals determined statistically significant differences in rates. The 95\% confidence intervals were provided by CDC WONDER and were calculated using methods outlined in the agency's technical appendix. ${ }^{28}$

To assess absolute changes in mortality, we calculated the average year-to-year changes in mortality to account for fluctuating trends between 1999 and 2016. This average provided a measure of absolute rate increases that was comparable across racial-ethnic groups and would not be influenced by differences in baseline mortality rates or population size. We took the average for the 17 years during 19992016 and, to capture recent trends, the last five years (2012-16).

To account for random year-to-year variation in mortality data, we used the Joinpoint Regression Program, ${ }^{30}$ based on the Monte Carlo permutation method, to model the trend lines that best fit the 17 annual mortality rates for each cause of death. ${ }^{31}$ The model identified points of inflection, or joinpoints-the years during 1999-2016 when changes in mortality trends (slopes) were statistically significant-and calculated the annual percentage rate change (APC, the slope for the interval between the joinpoints) and the average annual percentage change (AAPC, the slope for the entire period (1999-2016) based on the weighted average ${ }^{32}$ of the APCs). The program generated 95\% confidence intervals for the APC and AAPC estimates and conducted tests of significance to determine whether the slope for either differed significantly from zero (ie, whether mortality increased or decreased during the period) and whether the slope (APC) for any interval differed significantly from that of the preceding interval (ie, whether mortality trends changed significantly after the joinpoint year). We considered changes in mortality trends with a $\mathrm{P}$ value $\leq 0.05$ to be statistically significant. Joinpoint analysis was not conducted when mortality rates were unavailable for any of the 17 years.

In summary, we examined absolute changes in mortality rates with three measures: the average yearto-year change during 1999-2016 and 2012-16 and excess deaths attributable to increasing mortality rates. We estimated attributable deaths by applying the age adjusted mortality rate of the previous year to the population denominator and comparing with observed deaths for each year between 2000 and 2016. Relative changes (percentage increases) in mortality were examined with four measures: the relative difference (two point comparisons) between mortality rates in 1999 versus 2016 and in the nadir year versus 2016, as well as the relative change in modeled mortality trends for the 1999-2016 period (AAPC) and intervals between joinpoints (APC).

Although the international literature and statistical offices in many countries have moved away from categorizing data by race, US vital statistics continue to be classified by four racial groups established in 1997 by the Office of Management and Budget: American Indian or Alaskan Native, Asian or Pacific Islander, black or African American, and white. Ethnicity is classified based on Hispanic origin: Hispanic or Latino, not Hispanic or Latino, or not stated. $^{33}$ Race and Hispanic origin are treated as distinct concepts: Hispanic and Latino Americans may be of any race.

In our study of US vital statistics we therefore stratified results by sex and for fiveracial-ethnic groups: Hispanics of all races, non-Hispanic American Indians and Alaskan Natives, non-Hispanic Asians and Pacific Islanders, non-Hispanic blacks, and non-Hispanic whitess. As defined by the Office of Management and Budget, ${ }^{33}$ American Indians or Alaskan Natives include people with origins in (descended from the original peoples of) North and South America (including Central America) and who maintain tribal affiliation or community attachment. Asians include people with origins in the Far East, Southeast Asia, or the Indian subcontinent (eg, Cambodia), China, India, Japan, Korea, Malaysia, Pakistan, the Philippine Islands, Thailand, or Vietnam. Pacific Islanders include people with origins in Hawaii, Guam, Samoa, or other Pacific Islands. Whites include people with origins in Europe, the Middle East, or North Africa. Blacks include people with origins in the black racial groups of Africa.

These broad categories encompass diverse populations with different backgrounds, but further disaggregation was not feasible owing to small death counts. In 1999, the population (ages 25-64 years) and death counts (all causes), respectively, were 1113901 and 4526 for non-Hispanic American Indians and Alaskan Natives, 6105344 and 9436 for non-Hispanic Asians and Pacific Islanders, 16999288 and 101202 for non-Hispanic blacks, 105547575 and 369217 for non-Hispanic whites, and 15844820 and 35390 for Hispanics. In 2016, the corresponding values were 1382239 and 8160 for non-Hispanic American Indians and Alaskan Natives, 11115806 and 16578 for non-Hispanic Asians and Pacific Islanders, 21753829 and 121166 for non-Hispanic blacks, 106675849 and 462495 for non-Hispanic whites, and 28469499 and 63807 for Hispanics. Data were lacking to stratify mortality by educational attainment or other socioeconomic variables.

We examined geographic patterns using the 2013 National Center for Health Statistics urbanrural classification scheme, ${ }^{34}$ which recognizes four metropolitan categories (large central metro, metropolitan statistical areas of $\geq 1$ million population containing the largest principal city; large fringe metro, metropolitan statistical areas of $\geq 1$ million population that do not qualify as large central metro counties; medium metro, metropolitan statistical areas with populations of 250 000-999 999; and small metro, metropolitan statistical areas with populations of <250000) and two non-metropolitan categories (micropolitan statistical areas ${ }^{34}$ and non-core counties that do not qualify as micropolitan). 


\section{Public involvement}

Engagement with community groups with large representation by African Americans raised awareness about potential inattention-within the scientific community and the news media-to increasing mortality rates among populations of color. Stakeholders with interests in minority health will help disseminate the results of this study.

\section{Results}

Among the 20 broad categories that contributed to all cause mortality, mortality rates in midlife (ages 25-64 years) increased in 13 categories during the 19992016 study period. Four categories had unreliable data (owing to small death counts): diseases of the eye and adnexa, diseases of the ear and mastoid process, perinatal conditions, and codes for special purposes. Midlife mortality rates decreased in the remaining three categories-infectious and parasitic diseases, neoplasms, and diseases of the musculoskeletal system and connective tissue.

Of the 13 broad categories with increased midlife mortality rates, the largest proportional increases involved deaths from external causes, such as overdoses and transport incidents (fig 1). However, midlife mortality rates also increased for digestive diseases, such as alcohol related liver disease; respiratory diseases, such as chronic lower respiratory tract disease; endocrine, nutritional, and metabolic diseases, such as diabetes and obesity; diseases of the nervous system, such as dementia; mental and behavioral disorders; genitourinary diseases, such as renal failure; diseases of the skin and subcutaneous tissue; and pregnancy, childbirth, and the puerperium. Mortality rates in three additional categories were stable or decreased over a period of years, reached a nadir, and then experienced a statistically significant increase: these included circulatory diseases, such as hypertensive disease; congenital malformations, deformations, and chromosomal abnormalities; and symptoms, signs, and abnormal findings. Mortality from diseases of the blood and immune mechanism increased among non-Hispanic whites only.

Midlife mortality trends by race and ethnicity

Between 1999 and 2016, midlife all cause mortality increased by $5.2 \%$ (AAPC $0.2 \%$, 95\% confidence interval $0.1 \%$ to $0.4 \%$ ) among non-Hispanic whites, but the relative increase was much greater $(26.6 \%$; AAPC $1.5 \%, 1.0 \%$ to $1.9 \%$ ) among non-Hispanic American Indians and Alaskan Natives (fig 2). All cause mortality rates exhibited retrogression, declining until 2009 among non-Hispanic Asians and Pacific Islanders, 2010 among non-Hispanic blacks, 2011 among Hispanics, and 2012 among nonHispanic whites, but then plateauing or increasing. The progress these populations had achieved by reducing midlife mortality from certain diseases (eg, ischemic heart disease, cancer, HIV infection) was offset by statistically significant increases in mortality from external causes-notably drug overdoses, alcohol poisoning, and suicides-but also from a variety of organ diseases.

Tables 1-4 show mortality rates stratified by race and ethnicity. Table 1 presents mortality rates for broad categories of causes of death, such as diseases of the digestive system (see supplemental figures S1-S16 for trends in 16/20 broad categories). Tables 2 and 3 provide data for specific conditions within the broad categories that were leading contributors to increasing

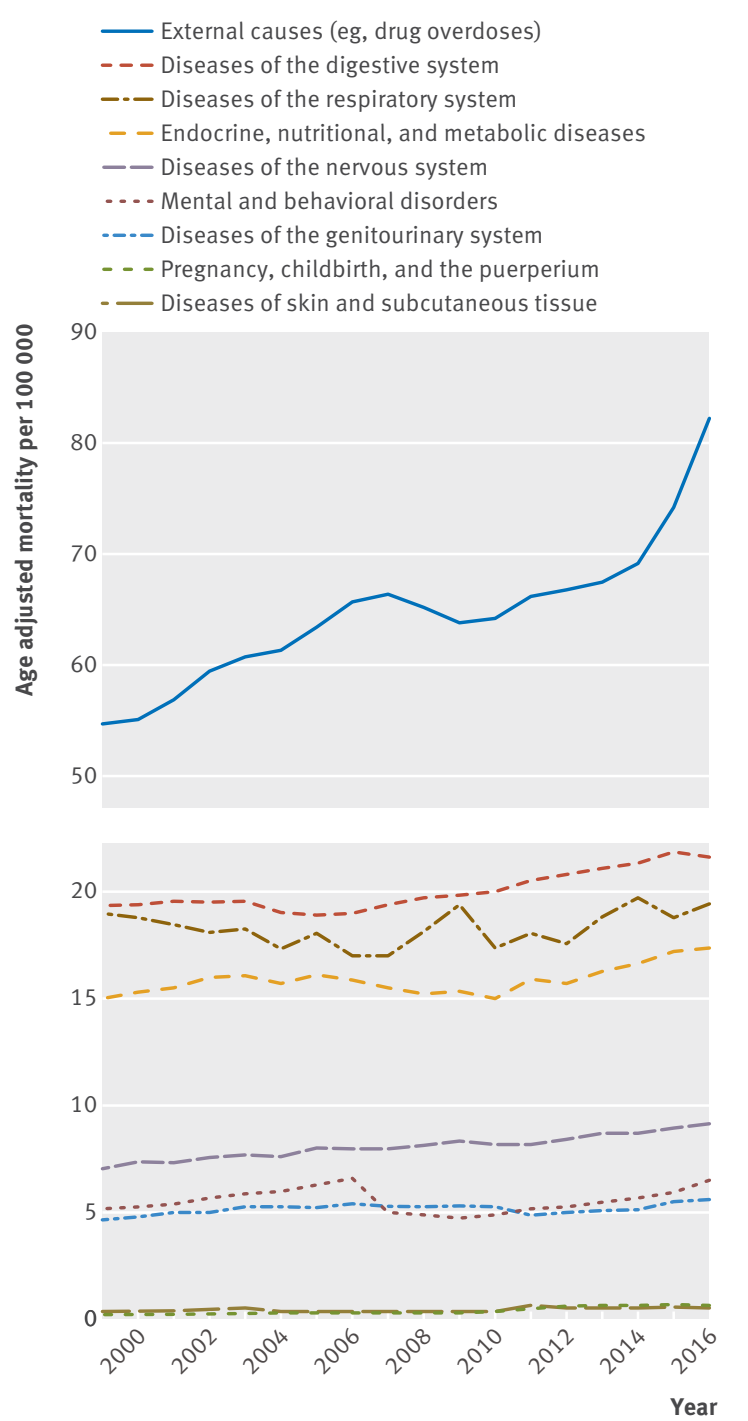

Fig 1 | Cause specific mortality rates among US adults aged 25-64 years (midlife), 1999-2016, for $9 / 13$ categories with increased midlife mortality rates. All cause mortality was classified into 20 broad categories (see text). 13 categories experienced an increase in midlife (25-64 years) mortality rates between 1999 and 2016, nine of which are shown here. Mortality rates for three additional categories were stable, or decreased over a period of years, but then increased significantly after reaching a nadir: these included circulatory diseases; congenital malformations, deformations, and chromosomal abnormalities; and symptoms, signs, and abnormal findings, not elsewhere classified. Mortality from diseases of the blood and immune mechanism increased among non-Hispanic whites only 

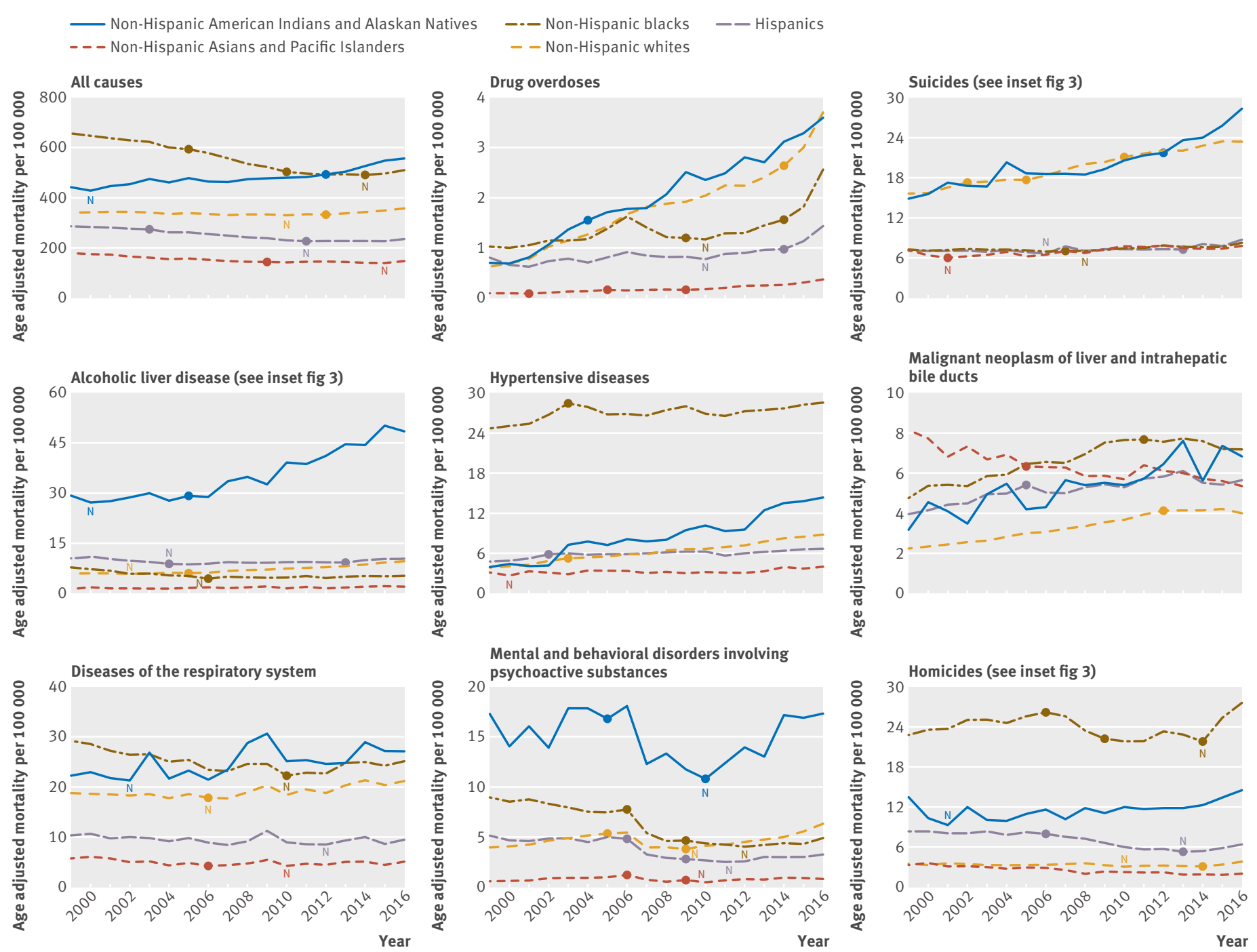

Fig 2 | Age adjusted all cause and cause specific mortality rates in US adults aged 25-64 years (midlife), 1999-2016, by race-ethnicity. Nadir (N) represents mortality rate that was statistically significantly below that of 2016 . Solid circles denote joinpoints-points of inflection when mortality trend lines (not shown) changed significantly (P<0.05). See supplemental file for trend lines and larger renditions of each graph

midlife mortality among non-Hispanic whites (table 2) and populations of color (table 3); figure 2 shows the trends over time. The online supplement provides more details, including full size renditions of each panel in figure 2 (figs S17-S25), color coded versions of tables 1-3 that help visualize trends (tables S1-S3), tables that present mortality trends across racialethnic groups (tables S4-S7), joinpoint regression results for determining the statistical significance of changing trends (table S8), and a joinpoint chartbook with 241 graphs that plot trend lines, calculated by the regression model, for each cause of death and racialethnic group.

These data show that cause specific mortality rates increased across multiple racial and ethnic groups during 1999-2016. In many cases, such as deaths from external causes, non-Hispanic whites experienced the largest relative increases in midlife mortality rates, and, because of their population size, the largest absolute number of deaths. Mortality rates among non-Hispanic whites increased for many conditions (table 2), but the phenomenon was not restricted to non-Hispanic whites. Substantial increases in cause specific mortality rates occurred among nonHispanic American Indians and Alaskan Natives, nonHispanic blacks, Hispanics, and non-Hispanic Asians and Pacific Islanders (table 3). These mortality rates often exhibited retrogression-that is, declined for a period of years but then stabilized or experienced a statistically significant increase after reaching a nadir (fig 2 and insets in fig 3). In many cases, the absolute increase in cause specific mortality rates among people of color and Hispanics rivaled that of non-Hispanic whites, becoming more pronounced in recent years.

Non-Hispanic American Indians and Alaskan Natives Although the non-Hispanic American Indian and Alaskan Native population was much smaller than that of non-Hispanic whites, members of that population faced greater absolute risks of death and a larger relative increase in mortality from certain conditions. Table 3 presents the data for the leading contributors 
Table 1 | Mortality rates from all causes, external causes, and organ diseases in US adults aged 25-64 years (midlife), 1999-2016, by race-ethnicity (see supplemental file for detailed table, including ICD-10 codes for causes of death, data for intervening years 2000-15, nadirs, and fitted models) Age adjusted mortality rates (deaths $/ 100000$ ), by year Changes in mortality rates

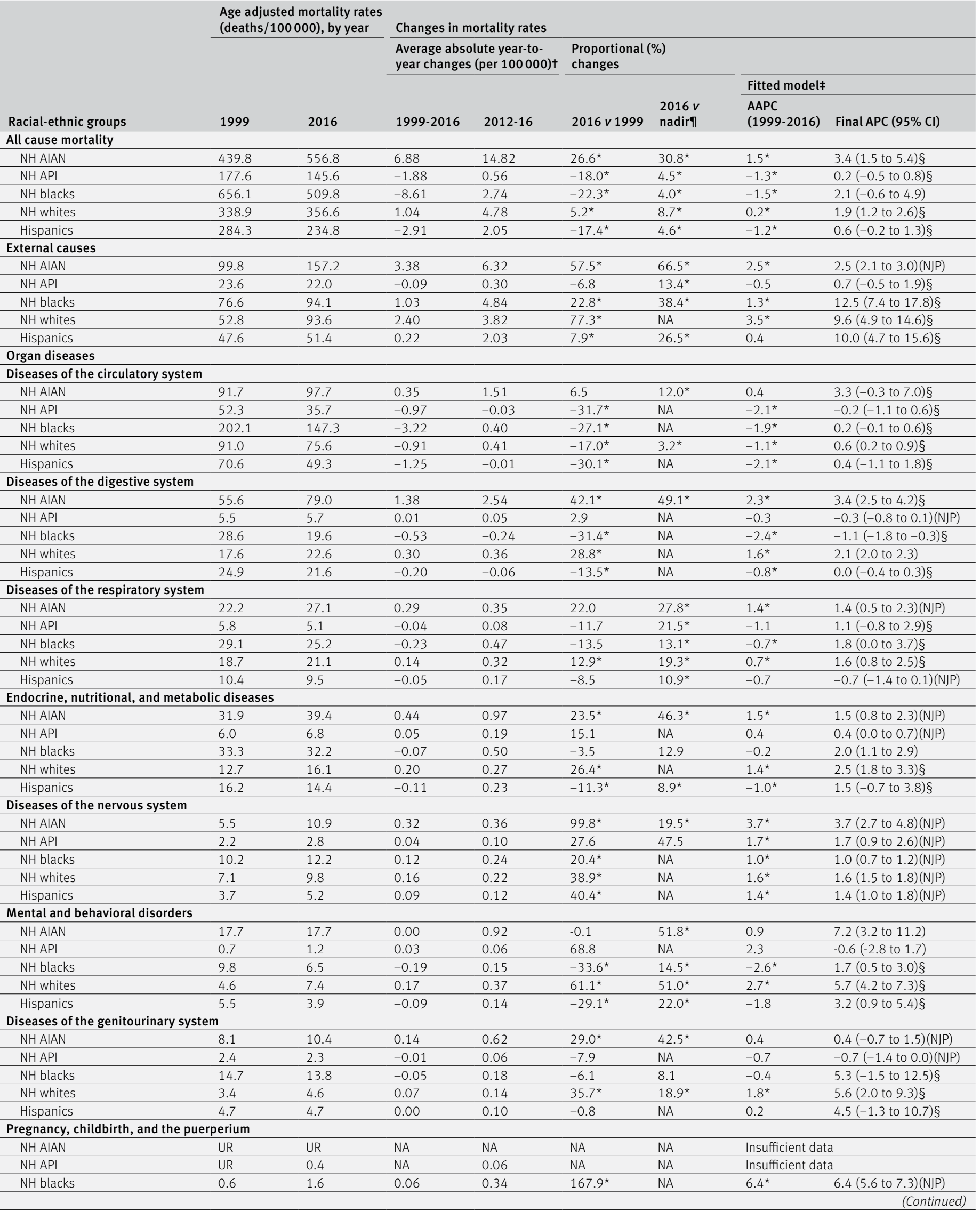


Table 1 | Mortality rates from all causes, external causes, and organ diseases in US adults aged 25-64 years (midlife), 1999-2016, by race-ethnicity (see supplemental file for detailed table, including ICD-10 codes for causes of death, data for intervening years 2000-15, nadirs, and fitted models) Age adjusted mortality rates (deaths/100 000), by year

Changes in mortality rates Average absolute year-to- Proportional (\%) year changes (per 100000)† changes

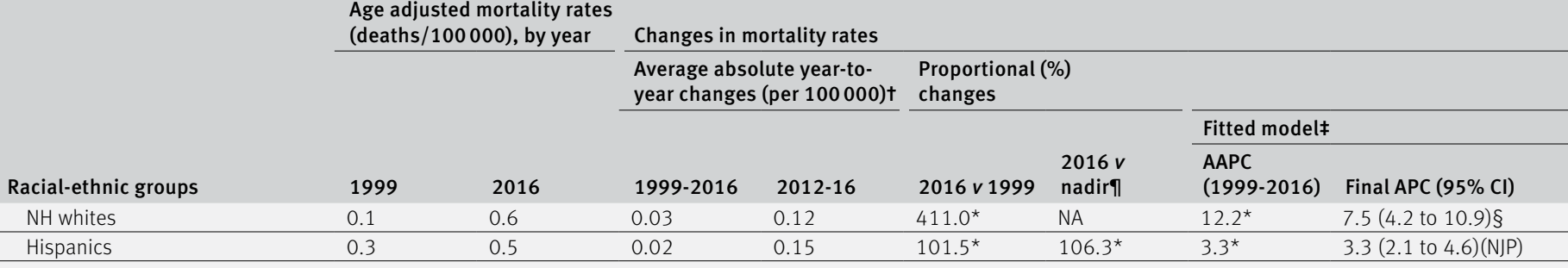

$\mathrm{APC}=$ annual percentage change (slope for intervals between joinpoints): $\mathrm{AAPC}=$ average annual percentage change (slope for entire (1999-2016) period based on weighted average of $\mathrm{APCS}$ ); $\mathrm{NH}=$ non-Hispanic; AIAN=American Indians and Alaskan Natives; API=Asians and Pacific Islanders; NA=not applicable (data inadequate for calculation); NJP=no joinpoint (fitted slope had no significant inflection during 1999-2016, values represent AAPC for 1999-2016); UR=unreliable data ( $<20$ deaths from specified cause of death in given year and racial-ethnic group). ${ }^{*} \mathrm{P}<0.05$.

tAverage year-to-year changes (from 1999 to 2016) in absolute mortality rates (deaths/100 000).

IPercent increase in mortality rate relative to intervening year between 1999 and 2016 when the mortality rate reached its lowest value, which was statistically significantly below the 2016 mortality rate. Nadir years and year-by-year mortality rates are provided in table S1 of the supplemental file.

¥Slopes from fitted model, in which joinpoint analysis ${ }^{30}$ was used to plot trend lines that best fit the 17 annual mortality rates between 1999 and 2016 . Joinpoints (see full table in the supplemental file) are points of inflection when mortality trend lines experienced a statistically significant change. For brevity, table presents APC values only for final interval ending in 2016 (or for 1999-2016 when no joinpoints were identified). (Supplemental file S1 provides the joinpoint years for each cause of death. See table S8 for all AAPC values, APC values for every segment, related $95 \%$ confidence intervals and P values, and joinpoint chartbook showing fitted model for each cause of death and racial-ethnic group.)

$\S A P C$ (slope) for interval ending in 2016 differed significantly $(\mathrm{P}<0.05)$ from slope of preceding period.

Table 2 | Mortality rates by leading causes of death in non-Hispanic whites aged 25-64 years (midlife), 1999-2016 (see supplemental file for detailed table, including ICD-10 codes for causes of death, data for intervening years 2000-15, nadirs, and fitted models)

\begin{tabular}{|c|c|c|c|c|c|c|c|c|c|}
\hline \multirow[b]{4}{*}{ Causes of death } & & & \multicolumn{6}{|c|}{ Changes in mortality rates } & \multirow{4}{*}{$\begin{array}{l}\text { Excess } \\
\text { deaths } \\
(1999- \\
2016)\end{array}$} \\
\hline & \multirow{2}{*}{\multicolumn{2}{|c|}{$\begin{array}{l}\text { Age adjusted } \\
\text { mortality rates } \\
\text { (deaths } / 100000 \text { ), } \\
\text { by year }\end{array}$}} & \multicolumn{2}{|c|}{$\begin{array}{l}\text { Average absolute year- } \\
\text { to-year changes } \\
\text { (per } 100000) \dagger\end{array}$} & \multicolumn{2}{|c|}{$\begin{array}{l}\text { Proportional (\%) } \\
\text { changes }\end{array}$} & & & \\
\hline & & & \multirow[b]{2}{*}{ 1999-2016 } & \multirow[b]{2}{*}{ 2012-16 } & \multirow[b]{2}{*}{$\begin{array}{l}2016 v \\
1999\end{array}$} & \multirow[b]{2}{*}{$\begin{array}{l}2016 \mathrm{~V} \\
\text { nadirף }\end{array}$} & \multicolumn{2}{|l|}{ Fitted model¥ } & \\
\hline & 1999 & 2016 & & & & & $\begin{array}{l}\text { AAPC (1999- } \\
2016)\end{array}$ & Final APC $(95 \% \mathrm{Cl})$ & \\
\hline \multicolumn{10}{|l|}{ External causes } \\
\hline Drug overdoses & 6.2 & 37.0 & 1.81 & 2.91 & $494.3^{\star}$ & NA & $11.1^{\star}$ & $20.0(6.2$ to 35.7$) \S$ & 33003 \\
\hline Alcohol poisoning & 0.2 & 1.2 & 0.06 & 0.01 & $674.5^{\star}$ & NA & $12.3^{*}$ & $2.1(-0.5$ to 4.9$) \S$ & 1146 \\
\hline Pedestrian/cyclist/motorcycle injury & 3.4 & 5.1 & 0.10 & 0.14 & $50.1^{\star}$ & NA & $2.4^{*}$ & $9.4(-1.4$ to 21.5$)$ & 1404 \\
\hline $\begin{array}{l}\text { Miscellaneous land/other transport } \\
\text { accidents }^{\mathrm{a}}\end{array}$ & 6.7 & 7.2 & 0.03 & 0.27 & $7.8^{\star}$ & $23.5^{*}$ & 0.2 & $2.8(1.5$ to 4.0$)$ & 561 \\
\hline Other forms of accidental poisoning ${ }^{b}$ & 0.3 & 0.7 & 0.02 & 0.03 & $139.1^{\star}$ & NA & $5.1^{*}$ & 5.1 (4.2 to 6.0$)(\mathrm{NJP})$ & 410 \\
\hline Falls, drowning, fire ${ }^{c}$ & 3.7 & 4.4 & 0.04 & 0.03 & $19.4^{*}$ & NA & $1.0^{\star}$ & $0.2(-0.1$ to 0.6$) \S$ & 768 \\
\hline Suicide & 15.6 & 23.3 & 0.45 & 0.35 & $49.4^{\star}$ & NA & $2.5^{\star}$ & $1.8(1.0$ to 2.5$) \S$ & 8300 \\
\hline \multicolumn{10}{|l|}{ Diseases of the circulatory system } \\
\hline Hypertensive diseases & 3.8 & 8.8 & 0.29 & 0.36 & $129.8^{\star}$ & NA & $5.1^{\star}$ & $4.2(3.9$ to 4.6$) \S$ & 5318 \\
\hline Other heart disease ${ }^{d}$ & 14.2 & 15.0 & 0.05 & 0.33 & $6.0^{*}$ & $15.6^{*}$ & $0.4^{\star}$ & $2.9(2.1$ to 3.8$) \S$ & 916 \\
\hline Venous/lymphatic diseases & 0.7 & 1.0 & 0.02 & 0.01 & $51.5^{\star}$ & NA & $1.3^{*}$ & 1.3 (0.7 to 2.0$)(\mathrm{NJP})$ & 376 \\
\hline Pulmonary heart disease & 2.5 & 2.5 & 0.01 & 0.06 & 3.6 & $19.7^{\star}$ & 0.0 & $1.7(0.8$ to 2.5$) \S$ & 93 \\
\hline \multicolumn{10}{|l|}{ Diseases of the digestive system } \\
\hline Alcoholic liver disease & 5.8 & 9.4 & 0.21 & 0.37 & $62.4^{\star}$ & $63.0^{*}$ & $2.9^{\star}$ & $4.1(3.7$ to 4.5$) \S$ & 3901 \\
\hline \multicolumn{10}{|l|}{ Mental and behavioral disorders } \\
\hline $\begin{array}{l}\text { Mental/behavioral disorders involving } \\
\text { psychoactive substances }\end{array}$ & 4.0 & 6.3 & 0.14 & 0.40 & $58.9^{*}$ & $66.7^{\star}$ & $2.6^{\star}$ & 7.4 (5.3 to 9.5$) \S$ & 2493 \\
\hline Organic mental disorders & 0.2 & 0.6 & 0.02 & -0.03 & $185.9^{*}$ & NA & $6.1^{\star}$ & $-8.9(-17.3$ to 0.4$) \S$ & 442 \\
\hline \multicolumn{10}{|l|}{ Infectious and parasitic diseases } \\
\hline Miscellaneous infectious diseases ${ }^{e}$ & 3.7 & 5.7 & 0.12 & 0.14 & $53.9^{\star}$ & NA & $2.4^{*}$ & 2.4 (2.2 to 2.7$)(\mathrm{NJP})$ & 2149 \\
\hline \multicolumn{10}{|l|}{ Neoplasms } \\
\hline Liver cancer & 2.2 & 4.0 & 0.11 & 0.01 & $80.0^{\star}$ & NA & $3.7^{\star}$ & $0.0(-1.3$ to 1.3$) \S$ & 1931 \\
\hline Cancer of lip/oral cavity/pharynx & 1.9 & 2.1 & 0.01 & 0.04 & $10.5^{\star}$ & $23.5^{\star}$ & 0.4 & $1.8(0.6$ to 3.0$) \S$ & 215 \\
\hline Pancreatic cancer & 5.3 & 5.5 & 0.01 & 0.03 & 3.3 & $7.6^{*}$ & $0.3^{*}$ & 0.3 (0.2 to 0.5$)(\mathrm{NJP})$ & 188 \\
\hline \multicolumn{10}{|c|}{ Endocrine, nutritional, and metabolic diseases } \\
\hline Obesity & 1.2 & 2.7 & 0.09 & 0.08 & $124.6^{*}$ & NA & $4.9^{*}$ & $3.3(2.9$ to 3.7$) \S$ & 1616 \\
\hline Diabetes & 9.3 & 10.1 & 0.05 & 0.11 & $8.9^{\star}$ & $14.2^{\star}$ & $0.5^{*}$ & $2.2(1.4$ to 3.0$) \S$ & 879 \\
\hline Metabolic disorders & 1.7 & 2.5 & 0.05 & 0.05 & $46.2^{\star}$ & NA & $2.0^{*}$ & 2.0 (1.8 to 2.3$)(\mathrm{NJP})$ & 858 \\
\hline Miscellaneous endocrine disorders ${ }^{f}$ & 0.5 & 0.6 & 0.01 & 0.01 & $31.1^{\star}$ & $38.9^{\star}$ & $1.7^{\star}$ & $1.7(1.2$ to 2.2$)(\mathrm{NJP})$ & 154 \\
\hline \multicolumn{10}{|l|}{ Diseases of the respiratory system } \\
\hline Chronic lower respiratory diseases & 11.5 & 12.3 & 0.04 & 0.17 & $6.6^{*}$ & $17.1^{*}$ & $0.5^{*}$ & $1.4(0.9$ to 1.9$) \S$ & 835 \\
\hline Lung diseases due to external agents & 0.8 & 1.3 & 0.03 & 0.04 & $60.3^{*}$ & NA & $2.4^{*}$ & 2.4 (2.0 to 2.8$)(\mathrm{NJP})$ & 542 \\
\hline Miscellaneous respiratory system disorders ${ }^{g}$ & 0.8 & 2.4 & 0.09 & 0.27 & $206.5^{\star}$ & $252.1^{\star}$ & $6.3^{\star}$ & $37.4(20.1$ to 57.1$) \S$ & 1709 \\
\hline \multicolumn{10}{|l|}{ Diseases of the nervous system } \\
\hline Alzheimer's/degenerative disorders & 0.6 & 1.1 & 0.03 & 0.06 & $76.8^{\star}$ & $84.5^{*}$ & $2.8^{*}$ & 2.8 (2.1 to 3.4$)(\mathrm{NJP})$ & 498 \\
\hline
\end{tabular}




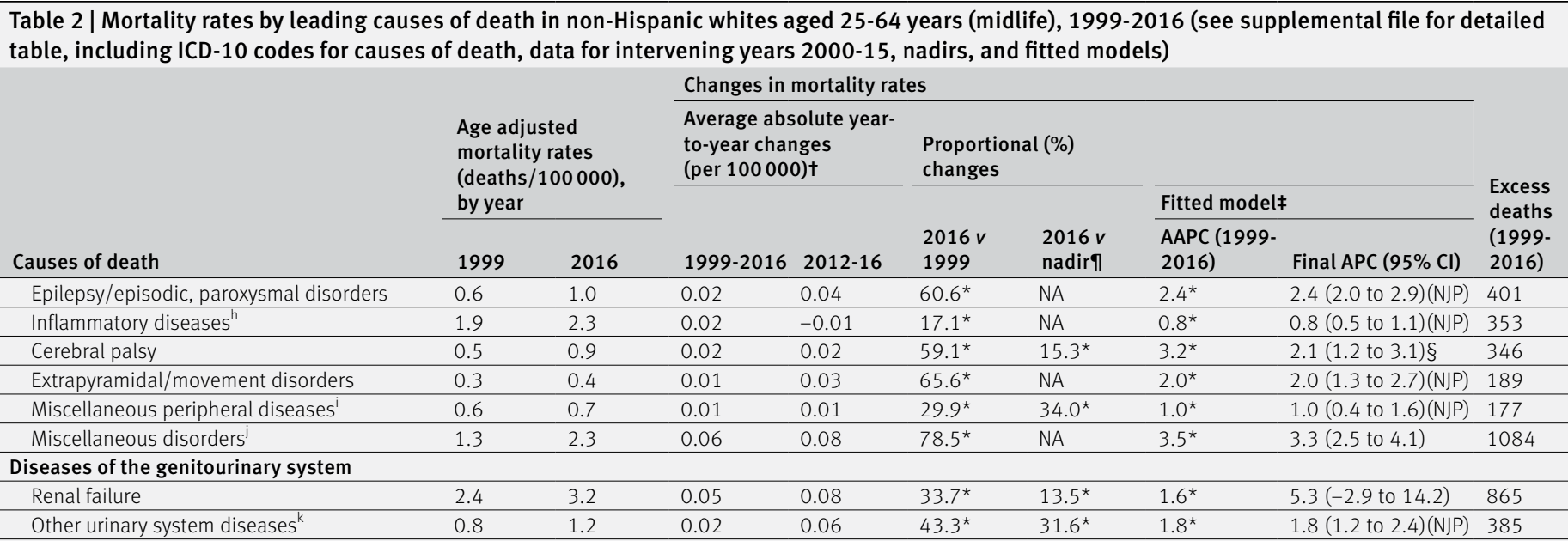

$A P C=$ annual percentage change (slope for intervals between joinpoints); $A A P C=$ average annual percentage change (slope for entire (1999-2016) period based on weighted average of APCs);

$N A=$ not applicable (data inadequate for calculation); NJP=no joinpoint (fitted slope had no significant inflection during 1999-2016, values represent AAPC for 1999-2016). ${ }^{a}=$ Accidents

involving other land, water transport, air/space, and other/unspecified transport; ${ }^{b}=$ accidental poisoning by organic solvents, halogenated hydrocarbons, other gases and vapors, pesticides, and unspecified chemicals and noxious substances; ${ }^{c}=$ includes deaths from submersion, smoke, and flames; ${ }^{d}=$ arrhythmias, cardiomyopathy, heart failure, cardiac arrest, myocarditis, and valvular and pericardial disease; ${ }^{e}=$ intestinal infections, tuberculosis, and zoonotic and other bacterial, sexually transmitted, spirochetal, chlamydial, rickettsial, central nervous system, arthropod-borne, and viral hemorrhagic infections; ${ }^{\mathrm{f}}=$ disorders of thyroid and other endocrine glands, malnutrition, and disorders of glucose regulation and pancreatic internal secretion; ${ }^{\mathrm{g}}=$ respiratory failure, not elsewhere classified, and other respiratory disorders; h=inflammatory diseases (eg, meningitis, encephalitis) and systemic atrophies (eg, Huntington's disease) affecting the central nervous system; ${ }^{i}=$ nerve/nerve root/plexus disorders, polyneuropathies, and other disorders of the peripheral nervous system, diseases of myoneural junction and muscle; ${ }^{i}=$ disorders of autonomic nervous system, hydrocephalus, toxic encephalopathy, and other disorders of nervous system, not elsewhere classified; ${ }^{k}=$ glomerular and renotubular interstitial diseases, urolithiasis, and other diseases of urinary system. See supplemental file for ICD-10 codes for each cause of death

${ }^{\star} \mathrm{P}<0.05$.

tAverage year-to-year changes (1999-2016) in absolute mortality rates (deaths/100 000)

IPercent increase in mortality rate relative to intervening year between 1999 and 2016 when the mortality rate reached its lowest value, which was statistically significantly below the 2016 mortality rate. Nadir years and year-by-year mortality rates are provided in table $\mathrm{S} 2$ of the supplemental file.

‡Slopes from fitted model, in which joinpoint analysis ${ }^{30}$ was used to plot trend lines that best fit the 17 annual mortality rates between 1999 and 2016 . Joinpoints (JP) are points of inflection when mortality trend lines experienced a statistically significant change. For brevity, table presents APC values only for final interval ending in 2016 (or for $1999-2016$ when no joinpoints were identified). (Supplemental file S2 provides the joinpoint years for each cause of death. See table S8 for all AAPC values, APC values for every segment, related $95 \%$ confidence intervals and P values, and joinpoint chartbook showing fitted model for each cause of death and racial-ethnic group.)

$\S A P C$ (slope) for interval ending in 2016 differed significantly $(P<0.05)$ from slope of preceding period.

Table 3 | Mortality rates among non-Hispanic American Indians and Alaskan Natives, blacks, Hispanics, and Asians and Pacific Islanders, aged 25-64 years (midlife), 1999-2016, by leading causes of death (see supplemental file for detailed table, including ICD-10 codes for causes of death, data for intervening years $2000-15$, nadirs, and fitted models)

\begin{tabular}{|c|c|c|c|c|c|c|c|c|c|}
\hline \multirow[b]{2}{*}{ Causes of death } & \multicolumn{2}{|c|}{$\begin{array}{l}\text { Age adjusted } \\
\text { mortality rates } \\
\text { (deaths/100 000), } \\
\text { by year }\end{array}$} & \multicolumn{2}{|c|}{$\begin{array}{l}\text { Average absolute } \\
\text { year-to-year } \\
\text { changes (per } \\
100000) \dagger\end{array}$} & \multicolumn{2}{|c|}{$\begin{array}{l}\text { Proportional (\%) } \\
\text { changes }\end{array}$} & & \multirow[b]{2}{*}{ Final APC $(95 \% \mathrm{Cl})$} & \multirow{2}{*}{$\begin{array}{l}\text { Excess } \\
\text { deaths } \\
(1999- \\
2016)\end{array}$} \\
\hline & 1999 & 2016 & $\begin{array}{l}1999- \\
2016\end{array}$ & $\begin{array}{l}2012- \\
16\end{array}$ & $\begin{array}{l}2016 v \\
1999\end{array}$ & $\begin{array}{l}2016 v \\
\text { nadir } 9\end{array}$ & $\begin{array}{l}\text { AAPC } \\
(1999- \\
2016)\end{array}$ & & \\
\hline \multicolumn{10}{|c|}{ Non-Hispanic American Indians and Alaskan Natives } \\
\hline Drug overdoses & 7.0 & 35.9 & 1.70 & 2.22 & $411.4^{\star}$ & NA & $10.9^{*}$ & 7.1 (5.7 to 8.5$) \S$ & 370 \\
\hline Alcoholic liver disease & 29.3 & 48.6 & 1.14 & 1.96 & $65.9^{*}$ & $78.0^{\star}$ & $3.5^{\star}$ & 5.3 (4.3 to 6.3$) \S$ & 254 \\
\hline Suicide & 14.9 & 28.4 & 0.80 & 1.40 & $91.2^{\star}$ & NA & $3.5^{\star}$ & $6.6(1.4$ to 12.1$)$ & 176 \\
\hline Hypertensive diseases & 3.9 & 14.3 & 0.61 & 1.01 & $269.3^{\star}$ & NA & $7.8^{*}$ & 7.8 (6.4 to 9.3)(NJP) & 134 \\
\hline Other heart disease ${ }^{a}$ & 15.7 & 20.1 & 0.26 & 0.79 & 27.7 & $34.9^{\star}$ & $0.9^{*}$ & $0.9(0.2$ to 1.6$)(\mathrm{NJP})$ & 57 \\
\hline Colorectal cancer & 6.7 & 10.8 & 0.24 & 0.24 & $60.6^{*}$ & NA & $2.0^{*}$ & 2.0 (1.1 to 3.0)(NJP) & 52 \\
\hline Liver cancer & 3.2 & 6.8 & 0.21 & 0.22 & $115.1^{\star}$ & NA & $4.0^{*}$ & 4.0 (2.7 to 5.2$)(\mathrm{NJP})$ & 45 \\
\hline Falls, drowning, fire ${ }^{b}$ & 8.3 & 11.6 & 0.19 & 0.59 & 39.3 & $49.0^{*}$ & 1.3 & 4.1 (1.3 to 6.9)§ & 43 \\
\hline Viral hepatitis & 2.3 & 4.8 & 0.15 & -0.12 & $112.1^{\star}$ & NA & $3.7^{\star}$ & 3.7 (1.5 to 5.9)(NJP) & 29 \\
\hline Diabetes & 28.6 & 30.9 & 0.13 & 0.66 & 7.9 & $37.7^{\star}$ & 0.9 & $3.7(0.7$ to 6.7$) \S$ & 38 \\
\hline Homicide & 13.5 & 14.5 & 0.06 & 0.56 & $7.6^{\star}$ & $55.3^{*}$ & $1.2^{\star}$ & $1.2(0.3$ to 2.2$)(\mathrm{NJP})$ & 19 \\
\hline $\begin{array}{l}\text { Mental/behavioral disorders involving } \\
\text { psychoactive substances }\end{array}$ & 17.3 & 17.3 & 0.00 & 1.02 & 0.2 & $61.8^{*}$ & 1.1 & 9.0 (2.6 to 15.8$) \S$ & 6 \\
\hline Miscellaneous nervous system disorders ${ }^{c}$ & UR & 3.5 & NA & 0.05 & NA & $108.9^{*}$ & Insuffici & data & 24 \\
\hline Alcohol poisoning & 2.2 & 10.2 & NA & 0.21 & $366.6^{\star}$ & NA & Insufficie & data & 104 \\
\hline \multicolumn{10}{|l|}{ Non-Hispanic blacks } \\
\hline Drug overdoses & 10.2 & 25.5 & 0.90 & 2.51 & $149.6^{\star}$ & $119.1^{\star}$ & $5.8^{\star}$ & 28.7 (11.4 to 48.7)§ & 3187 \\
\hline Homicide & 22.8 & 27.6 & 0.29 & 1.15 & $21.4^{\star}$ & $27.2^{\star}$ & 1.1 & 11.3 (3.8 to 19.3$) \S$ & 1005 \\
\hline Hypertensive diseases & 24.7 & 28.5 & 0.23 & 0.40 & $15.5^{\star}$ & NA & $0.7^{\star}$ & $0.1(-0.2$ to 0.5$) \S$ & 725 \\
\hline Obesity & 2.3 & 5.1 & 0.16 & 0.20 & $120.7^{\star}$ & NA & $4.8^{*}$ & $9.6(1.4$ to 18.4$)$ & 545 \\
\hline Liver cancer & 4.8 & 7.2 & 0.14 & -0.10 & $49.5^{\star}$ & NA & $2.2^{\star}$ & $-1.8(-3.6$ to 0.0$) \S$ & 430 \\
\hline Miscellaneous nervous system disorders ${ }^{c}$ & 3.7 & 5.1 & 0.08 & 0.17 & $35.8^{\star}$ & NA & $2.2^{\star}$ & $2.2(1.8$ to 2.5$)(\mathrm{NJP})$ & 268 \\
\hline
\end{tabular}




\begin{tabular}{|c|c|c|c|c|c|c|c|c|c|}
\hline \multirow[b]{2}{*}{ Causes of death } & \multicolumn{2}{|c|}{$\begin{array}{l}\text { Age adjusted } \\
\text { mortality rates } \\
\text { (deaths/100 000), } \\
\text { by year }\end{array}$} & \multicolumn{2}{|c|}{$\begin{array}{l}\text { Average absolute } \\
\text { year-to-year } \\
\text { changes (per } \\
100000) \dagger\end{array}$} & \multicolumn{2}{|c|}{$\begin{array}{l}\text { Proportional (\%) } \\
\text { changes }\end{array}$} & & \multirow{2}{*}{$\begin{array}{l}\text { Excess } \\
\text { deaths } \\
(1999- \\
2016)\end{array}$} \\
\hline & 1999 & 2016 & $\begin{array}{l}1999- \\
2016\end{array}$ & $\begin{array}{l}2012- \\
16\end{array}$ & $\begin{array}{l}2016 v \\
1999\end{array}$ & $\begin{array}{l}2016 v \\
\text { nadirq }\end{array}$ & $\begin{array}{l}\text { AAPC } \\
(1999- \\
2016)\end{array}$ & Final APC $(95 \% \mathrm{Cl})$ & \\
\hline Pedestrian/cyclist/motorcycle injury & 5.4 & 6.6 & 0.08 & 0.31 & $23.7^{\star}$ & $36.5^{\star}$ & 1.2 & $5.1(3.4$ to 6.8$) \S$ & 265 \\
\hline Miscellaneous land/other transport accidents ${ }^{\mathrm{d}}$ & 6.4 & 7.5 & 0.07 & 0.45 & $17.7^{\star}$ & $42.8^{\star}$ & 1.1 & $6.5(2.6$ to 10.5$) \S$ & 264 \\
\hline Metabolic disorders & 2.4 & 3.5 & 0.06 & 0.13 & $43.2^{\star}$ & $47.2^{\star}$ & $2.0^{*}$ & $4.6(2.8$ to 6.5$) \S$ & 216 \\
\hline Miscellaneous respiratory system disorders ${ }^{e}$ & 1.3 & 2.4 & 0.06 & 0.18 & $75.8^{\star}$ & $87.3^{\star}$ & $3.5^{\star}$ & $8.7(2.8$ to 14.9$) \S$ & 212 \\
\hline Suicide & 7.2 & 8.2 & 0.06 & 0.14 & $13.7^{\star}$ & $17.7^{\star}$ & $0.6^{*}$ & $1.5(0.9$ to 2.0$) \S$ & 213 \\
\hline Organic mental disorders & 0.3 & 0.9 & 0.04 & -0.02 & $215.3^{*}$ & NA & $6.2^{*}$ & $-10.5(-31.5$ to 17.1$)$ & 119 \\
\hline Cerebral palsy & 0.6 & 1.2 & 0.03 & 0.03 & $93.4^{\star}$ & $\mathrm{NA}$ & $3.5^{\star}$ & $1.3(0.4$ to 2.1$)$ & 109 \\
\hline Alzheimer's disease/degenerative disorders & 0.4 & 0.6 & 0.01 & 0.01 & 54.1 & $64.9^{\star}$ & $2.5^{\star}$ & $2.5(1.2$ to 3.8$)(\mathrm{NJP})$ & 42 \\
\hline Lung diseases due to external agents & 1.6 & 1.6 & -0.00 & 0.05 & -1.1 & $30.1^{*}$ & 0.1 & $3.1(0.8$ to 5.4$) \S$ & 4 \\
\hline Pancreatic cancer & 8.1 & 7.8 & -0.01 & 0.15 & -3.1 & $10.6^{*}$ & -0.2 & $1.6(0.3$ to 2.9$) \S$ & (29) \\
\hline Miscellaneous infectious diseases ${ }^{f}$ & 12.2 & 11.5 & -0.04 & 0.12 & -5.8 & $8.9^{\star}$ & -0.6 & $2.1(0.0$ to 4.3$) \S$ & (134) \\
\hline Pulmonary heart disease & 6.3 & 5.5 & -0.05 & 0.09 & -12.3 & $17.9^{\star}$ & $-0.8^{*}$ & $1.5(0.2$ to 2.7$) \S$ & $(126)$ \\
\hline Chronic lower respiratory diseases & 13.7 & 11.7 & -0.12 & 0.17 & $-14.66^{\star}$ & $9.5^{*}$ & $-1.0^{\star}$ & $0.7(0.0$ to 1.3$) \S$ & (339) \\
\hline Alcoholic liver disease & 7.7 & 5.2 & -0.14 & 0.04 & $-31.59^{\star}$ & $20.4^{*}$ & $-2.3^{\star}$ & $1.2(0.3$ to 2.1$) \S$ & $(418)$ \\
\hline Car accidents & 6.2 & 3.2 & -0.18 & -0.03 & $-48.52^{*}$ & $25.5^{*}$ & $-4.2^{\star}$ & $6.9(-4.0$ to 19.0$) \S$ & (574) \\
\hline $\begin{array}{l}\text { Mental/behavioral disorders involving psychoactive } \\
\text { substances }\end{array}$ & 9.0 & 4.9 & -0.24 & 0.13 & $-45.13^{*}$ & $23.3^{*}$ & $-3.9^{*}$ & $1.4(-0.3$ to 3.2$) \S$ & (749) \\
\hline Diabetes & 27.1 & 22.4 & -0.28 & 0.10 & $-17.29^{*}$ & $7.0^{*}$ & -1.1 & $1.0(0.0$ to 2.0$)$ & $(852)$ \\
\hline Other heart disease & 37.7 & 32.2 & -0.32 & 0.78 & $-14.53^{*}$ & $13.8^{*}$ & $-0.9^{\star}$ & 2.3 (1.5 to 3.2$) \S$ & (948) \\
\hline \multicolumn{10}{|l|}{ Hispanics } \\
\hline Drug overdoses & 7.9 & 14.3 & 0.37 & 1.11 & $80.0^{\star}$ & $83.3^{*}$ & $4.3^{\star}$ & $22.4(-4.8$ to 57.3$)$ & 1,777 \\
\hline Hypertensive diseases & 4.7 & 6.6 & 0.11 & 0.21 & $40.6^{*}$ & NA & $1.9^{\star}$ & $0.8(0.3$ to 1.3$) \S$ & 410 \\
\hline Liver cancer & 4.0 & 5.6 & 0.10 & -0.01 & $41.8^{\star}$ & NA & $2.2^{\star}$ & $0.9(0.1$ to 1.8$) \S$ & 333 \\
\hline Suicide & 7.1 & 8.6 & 0.09 & 0.29 & $21.9^{*}$ & $28.9^{\star}$ & $1.2^{*}$ & $5.3(-0.3$ to 11.2$)$ & 426 \\
\hline Alcohol poisoning & 0.3 & 1.2 & 0.06 & 0.00 & $354.0^{*}$ & $657.7^{*}$ & $10.5^{*}$ & $0.8(-4.7$ to 6.6$) \S$ & 224 \\
\hline Obesity & 0.8 & 1.6 & 0.05 & 0.07 & $106.6^{\star}$ & NA & $3.8^{\star}$ & 3.8 (3.1 to 4.6$)(\mathrm{NJP})$ & 193 \\
\hline Metabolic disorders & 0.8 & 1.3 & 0.03 & 0.02 & $60.0^{*}$ & $\mathrm{NA}$ & $2.2^{\star}$ & $2.2(1.5$ to 3.0$)$ (NJP) & 110 \\
\hline Miscellaneous nervous system disorders ${ }^{c}$ & 1.0 & 1.5 & 0.03 & 0.03 & $42.0^{*}$ & $47.6^{\star}$ & $2.5^{\star}$ & $2.5(1.9$ to 3.0$)(\mathrm{NJP})$ & 99 \\
\hline Pedestrian/cyclist/motorcycle injury & 4.6 & 4.9 & 0.02 & 0.20 & 7.5 & $30.7^{\star}$ & 0.1 & $2.7(0.8$ to 4.6$)$ & 114 \\
\hline Alzheimer's disease/degenerative disorders & 0.3 & 0.5 & 0.02 & 0.02 & $108.7^{*}$ & NA & $3.2^{\star}$ & $3.2(1.7$ to 4.7$)(\mathrm{NJP})$ & 62 \\
\hline Epilepsy/episodic, paroxysmal disorders & 0.3 & 0.6 & 0.02 & 0.04 & $78.4^{*}$ & $46.5^{\star}$ & $1.5^{*}$ & 1.5 (0.1 to 2.9$)(\mathrm{NJP})$ & 56 \\
\hline Organic mental disorders & 0.2 & 0.4 & NA & 0.01 & $113.9^{*}$ & NA & \multicolumn{2}{|c|}{ Insufficient data } & 42 \\
\hline Alcoholic liver disease & 10.4 & 10.4 & 0.00 & 0.21 & 0.6 & $20.3^{*}$ & -0.2 & $4.0(0.6$ to 7.5$)$ & 131 \\
\hline Miscellaneous respiratory system disorders ${ }^{\mathrm{e}}$ & 0.4 & 0.5 & 0.01 & 0.03 & 41.8 & $79.0^{*}$ & $3.2^{*}$ & $3.2(1.7$ to 4.8$)(\mathrm{NJP})$ & 40 \\
\hline Miscellaneous peripheral nervous system diseases ${ }^{g}$ & 0.2 & 0.4 & 0.01 & 0.02 & $83.7^{\star}$ & NA & $2.0^{\star}$ & $2.0(0.3$ to 3.7$)(\mathrm{NJP})$ & 39 \\
\hline Miscellaneous land/other transport accidents ${ }^{\mathrm{d}}$ & 5.4 & 5.1 & -0.02 & 0.34 & -5.5 & $49.1^{\star}$ & -0.4 & $8.8(3.0$ to 15.0$) \S$ & 32 \\
\hline $\begin{array}{l}\text { Mental/behavioral disorders involving psychoactive } \\
\text { substances }\end{array}$ & 5.1 & 3.3 & -0.11 & 0.15 & $-35.4^{*}$ & $28.8^{\star}$ & -2.5 & $3.4(1.4$ to 5.6$) \S$ & (355) \\
\hline Homicide & 8.4 & 6.4 & -0.12 & 0.16 & $-23.5^{*}$ & $22.0^{*}$ & $-1.6^{*}$ & $7.0(2.6$ to 11.5$) \S$ & $(408)$ \\
\hline \multicolumn{10}{|l|}{ Non-Hispanic Asians and Pacific Islanders } \\
\hline Drug overdoses & 0.9 & 3.6 & 0.16 & 0.30 & $300.6^{*}$ & NA & $8.2^{\star}$ & $11.4(8.9$ to 14.0$) \S$ & 258 \\
\hline Hypertensive diseases & 3.1 & 4.0 & 0.05 & 0.19 & $28.3^{*}$ & $51.9^{\star}$ & $1.2^{\star}$ & $1.2(0.3$ to 2.0$)(\mathrm{NJP})$ & 93 \\
\hline Alcoholic liver disease & 1.2 & 2.0 & 0.04 & 0.04 & $62.9^{\star}$ & NA & $2.0^{\star}$ & $2.0(1.0$ to 3.1$)(\mathrm{NJP})$ & 68 \\
\hline Brain/central nervous system cancers & 1.3 & 2.0 & 0.04 & 0.08 & $56.6^{*}$ & $36.5^{*}$ & $1.4^{*}$ & $1.4(0.5$ to 2.4$)(\mathrm{NJP})$ & 61 \\
\hline $\begin{array}{l}\text { Mental/behavioral disorders involving psychoactive } \\
\text { substances }\end{array}$ & 0.6 & 0.8 & 0.01 & 0.03 & 39.2 & $73.1^{\star}$ & 2.7 & $8.2(3.0$ to 13.7$)$ & 16 \\
\hline Suicide & 7.2 & 7.8 & 0.03 & 0.04 & 7.4 & $29.7^{\star}$ & 0.7 & 1.7 (1.1 to 2.3$)$ & 73 \\
\hline \multicolumn{10}{|c|}{$\begin{array}{l}\text { APC=annual percentage change (slope for intervals between joinpoints); AAPC=average annual percentage change (slope for entire (1999-2016) period based on weighted average of APCs); } \\
\text { NA=not applicable (data inadequate for calculation); NJP=no joinpoint (fitted slope had no significant inflection during 1999-2016, values represent AAPC for 1999-2016): UR=unreliable data } \\
\text { ( }<20 \text { deaths from specified cause of death in given year and racial-ethnic group). a=Arrhythmias, cardiomyopathy, heart failure, cardiac arrest, myocarditis, and valvular and pericardial disease; } \\
\text { b=includes deaths from submersion, smoke, and flames; c=disorders of autonomic nervous system, hydrocephalus, toxic encephalopathy, and other disorders of nervous system, not elsewhere } \\
\text { classified; d=accidents involving other land, water transport, air/space, and other/unspecified transport; e=respiratory failure, not elsewhere classified, and other respiratory disorders; f=intestinal } \\
\text { infections, tuberculosis, and zoonotic and other bacterial, sexually transmitted, spirochetal, chlamydial, rickettsial, central nervous system, arthropod borne, and viral hemorrhagic infections; } \\
\text { g=nerve/nerve root/plexus disorders, polyneuropathies, and other disorders of the peripheral nervous system, diseases of myoneural junction and muscle. } \\
\begin{aligned} * \\
P\end{aligned} 0.05 \text {. }\end{array}$} \\
\hline
\end{tabular}

IPercent increase in mortality rate relative to intervening year between 1999 and 2016 when the mortality rate reached its lowest value, which was statistically significantly below the 2016 mortality rate. Nadir years and year-by-year mortality rates are provided in table S3 of the supplemental file.

\#Slopes from fitted model, in which joinpoint analysis ${ }^{30}$ was used to plot trend lines that best fit the 17 annual mortality rates between 1999 and 2016. Joinpoints (see full table in supplemental file) are points of inflection when mortality trend lines experienced a statistically significant change. For brevity, table presents APC values only for final interval ending in 2016 (or for 1999 2016 when no joinpoints were identified). (Supplemental file S3 provides the joinpoint years for each cause of death. See table S8 for all AAPC values, APC values for every segment, related $95 \%$ confidence intervals and P values, and joinpoint chartbook showing fitted model for each cause of death and racial-ethnic group.)

$\S A P C$ (slope) for interval ending in 2016 differed significantly $(P<0.05)$ from slope of preceding period. 


\begin{tabular}{|c|c|c|c|c|c|c|c|c|c|c|}
\hline \multirow[b]{3}{*}{ Variables } & \multicolumn{6}{|c|}{ Age adjusted mortality rate (per 100000 ) } & \multicolumn{4}{|c|}{ Proportional (\%) increase in mortality } \\
\hline & \multicolumn{3}{|c|}{ Women } & \multicolumn{3}{|l|}{ Men } & \multicolumn{2}{|c|}{2016 v 1999} & \multicolumn{2}{|c|}{$2016 v$ nadir } \\
\hline & 1999 & Nadir rate (year) & 2016 & 1999 & Nadir rate (year) & 2016 & Women & Men & Women & Men \\
\hline \multicolumn{11}{|c|}{ All cause mortality } \\
\hline NH AIAN & 340.0 & $321.6(2000)$ & 418.3 & 546.2 & $536.6(2000)$ & 705.1 & $23.0^{\star}$ & $29.1^{*}$ & $30.0^{*}$ & $31.4^{\star}$ \\
\hline NH API & 138.0 & $102.0(2014)$ & 108.1 & 222.1 & NA & 189.0 & $-21.7^{*}$ & $-14.9^{\star}$ & $5.9^{*}$ & NA \\
\hline NH blacks & 487.6 & $375.9(2012)$ & 386.4 & 856.3 & $617.3(2004)$ & 650.0 & $-20.7^{*}$ & $-24.1^{\star}$ & $2.8^{\star}$ & $5.3^{*}$ \\
\hline $\mathrm{NH}$ whites & 251.5 & $244.7(2010)$ & 267.6 & 428.8 & $413.0(2010)$ & 447.1 & $6.4^{*}$ & $4.3^{*}$ & $9.4^{*}$ & $8.2^{\star}$ \\
\hline Hispanics & 193.6 & $154.6(2011)$ & 161.2 & 377.3 & $294.2(2014)$ & 308.3 & $-16.7^{\star}$ & $-18.3^{\star}$ & $4.3^{\star}$ & $4.8^{*}$ \\
\hline \multicolumn{11}{|c|}{ External causes } \\
\hline NH AIAN & 57.8 & $49.5(2001)$ & 90.8 & 144.1 & $138.5(2000)$ & 226.8 & $57.2^{*}$ & $57.4^{*}$ & $83.4^{*}$ & $63.7^{\star}$ \\
\hline NH API & 15.4 & $11.2(2009)$ & 12.1 & 32.7 & $28.8(2009)$ & 35.0 & $-21.0^{*}$ & 7.0 & 8.2 & $21.4^{\star}$ \\
\hline NH blacks & 33.7 & $30.7(2008)$ & 41.1 & 125.9 & $109.6(2010)$ & 152.5 & $22.1^{*}$ & $21.1^{*}$ & $33.7^{\star}$ & $39.2^{\star}$ \\
\hline $\mathrm{NH}$ whites & 27.7 & NA & 54.8 & 78.2 & NA & 132.2 & $98.3^{*}$ & $69.1^{\star}$ & $\mathrm{NA}$ & $\mathrm{NA}$ \\
\hline Hispanics & 18.5 & $17.1(2008)$ & 21.8 & 75.6 & $62.8(2010)$ & 79.9 & $17.9^{*}$ & $5.6^{\star}$ & $27.8^{*}$ & $27.3^{*}$ \\
\hline \multicolumn{11}{|c|}{ Drug overdoses } \\
\hline NH AIAN & 5.1 & $4.6(2000)$ & 28.3 & 9.0 & $8.9(2000)$ & 43.9 & $457.0^{\star}$ & $386.8^{\star}$ & $509.5^{\star}$ & $395.8^{*}$ \\
\hline NH API & UR & $0.5(2004)$ & 1.6 & 1.4 & $1.3(2000)$ & 5.8 & NA & $308.2^{\star}$ & $192.5^{\star}$ & $353.1^{*}$ \\
\hline NH blacks & 5.1 & NA & 15.5 & 16.1 & $15.2(2010)$ & 36.7 & $201.7^{\star}$ & $127.8^{\star}$ & NA & $141.5^{*}$ \\
\hline $\mathrm{NH}$ whites & 3.4 & NA & 24.5 & 9.0 & NA & 49.3 & $611.5^{\star}$ & $445.9^{\star}$ & NA & NA \\
\hline Hispanics & 2.6 & $2.3(2000)$ & 6.7 & 13.2 & 9.9 (2001) & 21.6 & $158.9^{\star}$ & $64.2^{\star}$ & $194.0^{\star}$ & $118.8^{*}$ \\
\hline \multicolumn{11}{|c|}{ Alcohol induced causes } \\
\hline NH AIAN & 31.2 & $27.8(2000)$ & 53.7 & 65.7 & $57.6(2000)$ & 99.4 & $72.0^{\star}$ & $51.3^{*}$ & $93.2^{\star}$ & $72.7^{\star}$ \\
\hline NH API & UR & $0.5(2004)$ & 1.2 & 3.3 & NA & 5.1 & NA & $52.6^{*}$ & $125.1^{\star}$ & NA \\
\hline NH blacks & 7.1 & $4.4(2007)$ & 5.8 & 23.6 & $12.8(2012)$ & 14.3 & $-18.8^{\star}$ & $-39.3^{*}$ & $31.7^{\star}$ & $11.6^{*}$ \\
\hline NH whites & 4.4 & NA & 9.7 & 14.6 & $14.5(2000)$ & 21.4 & $120.3^{\star}$ & $46.5^{\star}$ & NA & $46.8^{\star}$ \\
\hline Hispanics & 4.0 & $3.4(2004)$ & 5.6 & 25.1 & $20.7(2012)$ & 22.7 & $38.5^{\star}$ & $-9.6^{*}$ & $66.2^{\star}$ & $10.0^{*}$ \\
\hline \multicolumn{11}{|l|}{ Suicide } \\
\hline NH AIAN & 7.0 & $5.0(2003)$ & 12.5 & 23.1 & NA & 44.9 & $77.6^{\star}$ & $94.8^{\star}$ & $147.5^{\star}$ & NA \\
\hline NH API & 3.8 & $3.2(2000)$ & 4.1 & 11.1 & $8.9(2001)$ & 11.9 & 7.3 & 7.4 & 27.3 & $33.9^{\star}$ \\
\hline NH blacks & 2.2 & $2.0(2006)$ & 3.1 & 13.0 & $12.1(2007)$ & 13.7 & $40.5^{*}$ & 5.7 & $56.0^{*}$ & $13.5^{\star}$ \\
\hline NH whites & 6.9 & NA & 11.7 & 24.4 & NA & 35.0 & $69.6^{\star}$ & $43.4^{\star}$ & $\mathrm{NA}$ & NA \\
\hline Hispanics & 2.4 & $2.1(2001)$ & 3.4 & 11.6 & $11.0(2006)$ & 13.7 & $41.9^{\star}$ & $17.5^{\star}$ & $63.6^{\star}$ & $24.6^{*}$ \\
\hline
\end{tabular}

to increasing mortality, sequenced by the number of attributable deaths. The surge in mortality during $1999-2016$ was driven by a $411.4 \%$ increase (AAPC $10.9 \%, 95 \%$ confidence interval $9.2 \%$ to $12.6 \%$ ) in drug overdose deaths, which included large year-toyear increases during 2012-16, matched only by that of non-Hispanic whites. Non-Hispanic American Indians and Alaskan Natives also experienced the largest proportional and year-to-year increases in mortality from alcohol related liver disease of any racial-ethnic group studied, with statistically significant increases after the last joinpoint. Proportional and year-to-year increases in suicides also exceeded those of other groups.

Between 1999 and 2016, non-Hispanic American Indians and Alaskan Natives experienced large increases in death rates from hypertensive diseases (269.3\%; AAPC $7.8 \%, 6.4 \%$ to $9.3 \%$ ), liver cancer (115.1\%; AAPC $4.0 \%, 2.7 \%$ to $5.2 \%$ ), viral hepatitis (112.1\%; AAPC $3.7 \%, 1.5 \%$ to $5.9 \%$ ), and diseases of the nervous system (99.8\%; AAPC 3.7\%, 2.7\% to $4.8 \%$ ); the proportional and year-to-year increases during 2012-16 exceeded those of other groups. This was the only population in which cancer mortality increased (colorectal cancer mortality in particular). Mortality rates also increased for diabetes, a category of circulatory disorders that includes arrhythmias and heart failure, respiratory and genitourinary disorders, mental and behavioral disorders (notably those involving psychoactive substances), homicides, transport accidents, and a category of accidents that includes falls and drownings. The latter increased by $49.0 \%$ after 2008 , at a faster year-to-year pace than occurred in other groups. In 2012-16, non-Hispanic American Indians and Alaskan Natives averaged the largest relative increase in midlife mortality from diabetes.

\section{Non-Hispanic blacks}

Historically high mortality rates among non-Hispanic blacks decreased substantially between 1999 and 2016, but this two point comparison obscured a statistically significant change in slope that began in 2014, when the decline in all cause mortality ended (table 1). The rate of fatal drug overdoses, the leading cause of excess deaths, increased by $149.6 \%$ 
- Non-Hispanic American Indians and Alaskan Natives - - - Non-Hispanic Asians and Pacific Islanders

-- Non-Hispanic blacks

- Non-Hispanic whites

- Hispanics
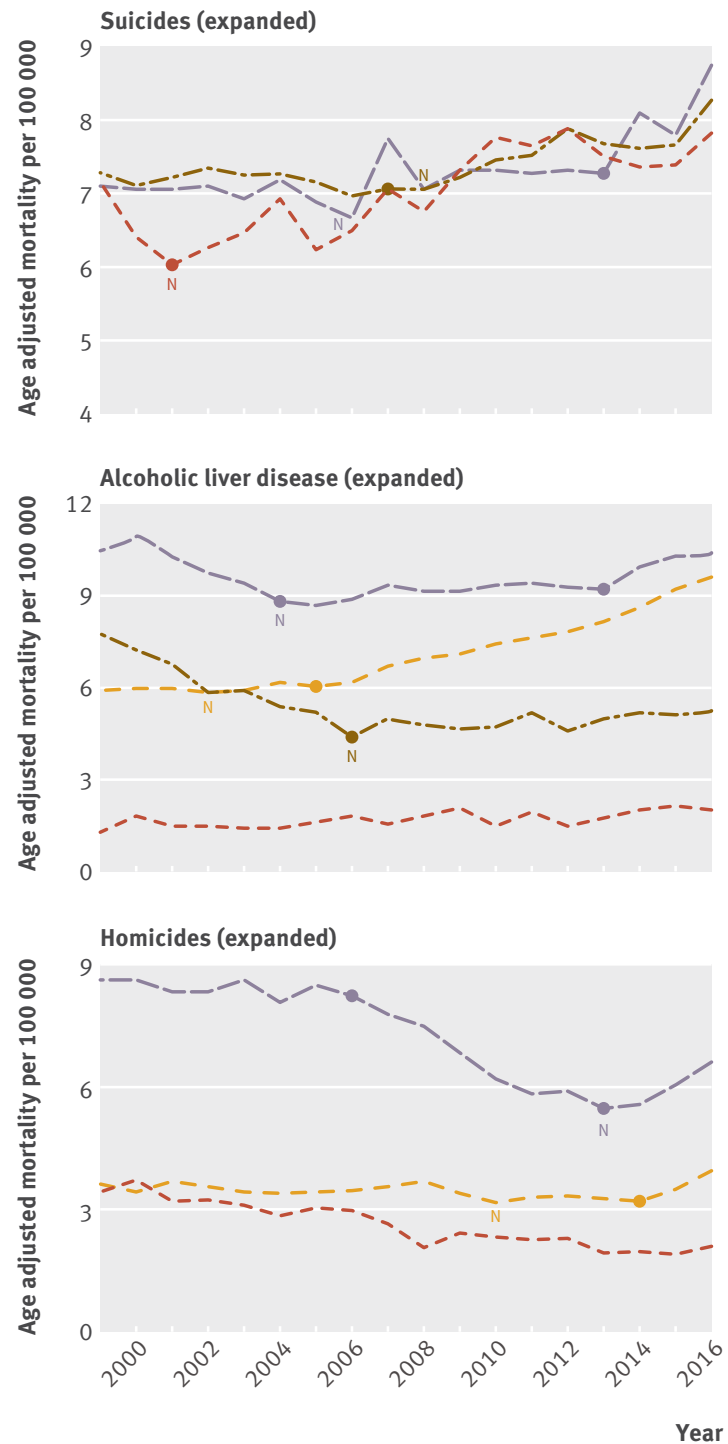

Fig 3 Age adjusted mortality rates in US adults aged 25-64 years (midlife), 1999-2016, for suicide, alcohol related liver disease, and homicides by race-ethnicity. The figure replots selected data from figure 2 against a modified y axis to help visualize mortality trends among groups with lower baseline mortality rates. Nadir (N) represents mortality rate that was statistically significantly below that of 2016 . Solid circles denote joinpoints-points of inflection when mortality trend lines (not shown) changed significantly ( $P<0.05)$. See supplemental file for trend lines and larger renditions of each graph

(AAPC 5.8\%, 95\% confidence interval 2.9\% to 8.9\%) between 1999 and 2016. Mortality from homicides increased by $27.2 \%$ after 2014 (post-2014 APC 11.3\%, 95\% confidence interval, $3.8 \%$ to $19.3 \%$ ), producing a greater proportional and year-to-year increase than occurred in any other racial-ethnic group. Retrogression occurred with mortality from alcohol related liver disease, which increased by $20.4 \%$ after 2006 (post-2006 APC 1.2\%, 0.3\% to 2.1\%); suicides, which increased by $17.7 \%$ after 2008 (post-2007 APC $1.5 \%, 0.9 \%$ to $2.0 \%$ ); and deaths from mental and behavioral disorders, notably those involving psychoactive substances, the latter increasing by 23.3\% after 2012. During 2012-16, midlife mortality from transport (eg, car, pedestrian, and motorcycle) accidents also increased among non-Hispanic blacks.

Additionally, non-Hispanic blacks experienced retrogression with a variety of organ diseases. After years of declining mortality, death rates increased for endocrine and metabolic disorders (eg, diabetes), certain circulatory disorders (eg, arrhythmias, heart failure)andinfectiousdiseases, respiratorydiseases(eg, chronic lower respiratory tract disease, lung diseases involving external agents (eg, pneumoconiosis)), and pancreatic cancer (table 3). Midlife mortality increased for hypertensive diseases, liver cancer, neurologic conditions (eg, cerebral palsy), and organic mental disorders (eg, vascular dementia). Obesity related mortality more than doubled (120.7\% increase; AAPC $4.8 \%, 2.9 \%$ to $6.7 \%$ ), producing higher year-to-year increases than in any other group, and the death rate from metabolic disorders also increased (AAPC 2.0\%, $1.3 \%$ to $2.7 \%$ ). The increase in mortality for certain conditions escalated during 2012-16; non-Hispanic blacks averaged the highest year-to-year increases in homicides, transport accidents, hypertensive diseases, and other circulatory, respiratory, endocrine, and nervous system diseases.

\section{Hispanics}

Although the Hispanic population generally exhibited lower absolute mortality rates than non-Hispanic whites-the so-called Hispanic paradox ${ }^{35}$-this population also experienced retrogression: all cause mortality decreased until 2011, after which the APC increased (table 1). The rate of fatal drug overdoses increased by $80.0 \%$ (AAPC $4.3 \%, 1.4 \%$ to 7.3\%). Alcohol related deaths showed retrogression: statistically significant increases occurred in the rate of fatal alcohol poisoning (AAPC 10.5\%, 1.2\% to $20.6 \%$ ), increasing by $657.7 \%$ after 2003 , and midlife mortality from alcohol related liver disease increased by $20.3 \%$ after 2004 (post-2013 APC 4.0\%, 0.6\% to 7.5\%). The midlife suicide rate increased during 1999 2016 (AAPC $1.2 \%, 0.2 \%$ to $2.1 \%$ ), increasing by $28.9 \%$ after 2006. Mortality rates from mental and behavioral disorders involving psychoactive substances increased by $28.8 \%$ after 2011 (post-2009 APC 3.4\%, 1.4\% to $5.6 \%)$.

Hispanics also experienced an increase in midlife mortality from organ diseases, including hypertensive diseases (AAPC 1.9\%, 0.9\% to 2.9\%), liver cancer (2.2\%, $1.3 \%$ to $3.0 \%)$, obesity $(3.8 \%, 3.1 \%$ to $4.6 \%)$, metabolic disorders $(2.2 \%, 1.5 \%$ to $3.0 \%)$, and various neurologic and mental disorders (table 3 ). Homicide rates increased after 2013, and fatal pedestrian, motorcycle, and other transport accidents increased after 2011, by 2012-16 outpacing the year-to-year 
increases in mortality experienced by non-Hispanic whites.

\section{Non-Hispanic Asians and Pacific Islanders}

Non-Hispanic Asians and Pacific Islanders were least impacted by increasing mortality rates. Although this population had the lowest absolute mortality rates, they experienced statistically significant cause specific increases in midlife mortality during 19992016, notably from drug overdoses $(300.6 \%$; AAPC $8.2 \%, 5.1 \%$ to $11.5 \%$ ) and alcohol related liver disease (62.9\%; AAPC $2.0 \%, 1.0 \%$ to $3.1 \%$ ). Suicide rates increased by 29.7\% after 2001 (post-2001 APC $1.7 \%, 1.1 \%$ to $2.3 \%$ ), and mortality from mental and behavioral disorders involving use of psychoactive substances increased by $73.1 \%$ after 2010 (post-2009 APC $8.2 \%, 3.0 \%$ to $13.7 \%$ ).

Although non-Hispanic Asians and Pacific Islanders exhibited few statistically significant increases in mortality from organ diseases during 1999-2016, they did experience a significant increase in midlife mortality from brain and other central nervous system cancers $(56.6 \%$; AAPC $1.4 \%, 0.5 \%$ to $2.4 \%)$. The average increase in midlife mortality from neurologic diseases was also significant (AAPC 1.7\%, 0.9\% to $2.6 \%$ ). Mortality from hypertensive diseases increased by $28.3 \%$, and retrogression occurred with diseases of the respiratory system.

\section{Midlife mortality trends by sex}

Among non-Hispanic whites, the relative increase in midlife all cause mortality was greater among women than among men $(6.4 \% v 4.3 \%)$, whereas the reverse occurred among non-Hispanic American Indians and Alaskan Natives (23.0\% v 29.1\%) (table 4). Post-nadir increases in all cause mortality among non-Hispanic blacks and Hispanics were also higher among men than among women $(5.3 \% v 2.8 \%$, 4.8\% $v 4.3 \%$, respectively). However, although men had higher absolute mortality rates for drug overdoses and suicides, the relative increase was higher among women. The relative increase in fatal drug overdoses was higher for women than for men among nonHispanic American Indians and Alaskan Natives (457.0\% v 386.8\%), non-Hispanic blacks (201.7\% v $127.8 \%)$, non-Hispanic whites (611.5\% v 445.9\%), and Hispanics (158.9\% v 64.2\%); data were lacking for non-Hispanic Asians and Pacific Islanders. The same pattern occurred with suicides among nonHispanic blacks, non-Hispanic whites, and Hispanics; men experienced the larger relative increase among non-Hispanic American Indians and Alaskan Natives.

\section{Midlife mortality trends by geography}

Across all racial-ethnic groups, midlife all cause mortality rates were higher in non-metropolitan areas (eg, rural) than metropolitan areas. Among nonHispanic whites, the relative increase in all cause mortality during 1999-2016 was greater in nonmetropolitan areas, whereas the reverse occurred among non-Hispanic American Indians and Alaskan
Natives (ie, larger relative increases in metropolitan areas). The same pattern was seen for suicides (table 5). With drug overdoses, the largest relative increases among non-Hispanic whites and Hispanics occurred in suburban areas of large cities (populations $\geq 1$ million) designated as fringe areas, ${ }^{34}$ whereas the largest relative increases among non-Hispanic blacks occurred in small cities (populations <250 000).

\section{Discussion}

Life expectancy in the United States has not kept pace with progress in other industrialized nations and is now decreasing. ${ }^{37}$ This study, like others, reports that mortality rates have increased since the 1990s, but the problem has older roots. According to a 2013 report by the National Research Council and Institute of Medicine, the "US health disadvantage" began decades ago and has grown more pervasive with time. ${ }^{38}$ That report documented poor health in nine domains: birth outcomes, injuries and homicides, adolescent pregnancy, HIV/AIDS, drug related mortality, obesity and diabetes, heart disease, chronic lung disease, and disability. The report identified deep, systemic causes for the US health disadvantage involving not only deficiencies in healthcare and the prevalence of risky behaviors but also socioeconomic inequalities, unhealthy environmental conditions, and detrimental public policies. $^{39}$

This study reaffirms the pervasiveness of the problem. Although drug overdoses accounted overwhelmingly for the excess deaths caused by increasing mortality rates, alcohol related diseases, suicides, unintentional injuries, and organ diseases involving multiple body systems together accounted for even more excess deaths. No single factor, such as opioids, explains this phenonemon. ${ }^{40}$ A more likely explanation is the systemic problems identified by the National Research Council and Institute of Medicine, ${ }^{38}$ which require upstream solutions. The prediction issued in 2013that conditions would worsen without bold policy action to tackle these root causes ${ }^{39}$-was followed by higher premature mortality. Tables 2 and 3 document many instances in which mortality rates in recent years experienced statistically significant increases, often eclipsing the slope (AAPC) for 1999-2016, suggesting that mortality in midlife is now increasing faster.

The work of Case and Deaton ${ }^{39}$ stimulated extensive media coverage. Stories typically featured white families-often in rust belt, Appalachian, or rural communities-struggling with opioid addiction. ${ }^{24-2641-43}$ This study suggests that the problem also affects non-white populations and has broader health implications (beyond addiction) than media coverage would suggest. While mortality rates among non-Hispanic whites experienced large increases during 1999-2016, they also rose simultaneously (and sometimes more substantively) among non-Hispanic American Indians and Alaskan Natives. Moreover, our study refutes prior assertions that mortality rates have improved for non-Hispanic blacks and Hispanics. This was once true, but current data now reveal a reversal 


\begin{tabular}{|c|c|c|c|c|c|c|}
\hline \multirow{3}{*}{ Variables } & \multicolumn{6}{|c|}{ Proportional increase in mortality $(\%$, deaths/100 $000(1999,2016))$} \\
\hline & \multicolumn{4}{|l|}{ Metro } & \multicolumn{2}{|l|}{ Non-metro } \\
\hline & Large central & Large fringe & Medium & Small & Micro & Non-core \\
\hline \multicolumn{7}{|l|}{ All causes } \\
\hline \multirow{2}{*}{ NH AIAN } & $30.5(361.4,471.7)^{\star}$ & & & & $22.4(570.5,698.5)^{\star}$ & \\
\hline & $27,6(346.4,442.1)^{\star}$ & $17.2(288.9,338.7)$ & $25.4(389.5,488.6)^{*}$ & $33.7(416.2,627.6)^{*}$ & $31.2(497.1,652.2)^{\star}$ & $15.3(649.0,748.4)^{\star}$ \\
\hline \multirow{2}{*}{ NH API } & $-17.6(174.0,143.3)^{\star}$ & & & & $-26.1(301.4,222.8)^{\star}$ & \\
\hline & $-17.2(172.6,143.0)^{\star}$ & $-17.2(141.6,117.2)^{\star}$ & $-15.7(222.5,187.5)^{\star}$ & $-9.3(175.7,160.7)$ & $-24.7(307.7,231.7)^{\star}$ & $-27.5(266.3,193.0)$ \\
\hline \multirow{2}{*}{ NH blacks } & $-22.9(649.0,500.7)^{\star}$ & & & & $-16.5(715.4,597.6)^{*}$ & \\
\hline & $-24.5(701.6,535.5)^{\star}$ & $-24.5(528.6,399.2)^{\star}$ & $-17.0(647.0,536.8)^{\star}$ & $-15.6(647.4,560.2)^{\star}$ & $-15.6(710.5,599.3)^{*}$ & $-17.5(721.3,595.4)^{\star}$ \\
\hline \multirow{2}{*}{ NH whites } & $2.6(331.3,339.9)^{\star}$ & & & & $16.9(371.3,434.2)^{\star}$ & \\
\hline & $3.1(345.5,315.0)^{*}$ & $3.1(304.7,314.1)^{\star}$ & $10.6(340.0,376.2)^{\star}$ & $10.8(349.7,391.9)^{\star}$ & $15.5(366.3,423.1)^{\star}$ & $18.9(378.4,449.9)^{\star}$ \\
\hline \multirow{2}{*}{ Hispanics } & $-17.3(280.2,231.7)^{\star}$ & & & & $-17.5(341.3,281.7)^{\star}$ & \\
\hline & $-13.7(289.4,230.2)^{\star}$ & $-13.7(224.6,193.7)^{\star}$ & $-10.0(295.9,266.4)^{\star}$ & $-13.2(294.9,260.5)^{\star}$ & $-13.6(328.3,283.8)^{\star}$ & $-24.6(368.3,27.6)^{\star}$ \\
\hline \multicolumn{7}{|c|}{ (2) } \\
\hline NH AIAN & $306.3(8.9,36.1)^{\star}$ & & & & NA (UR, 35.6) & \\
\hline $\mathrm{NH}$ API & $337.5(0.8,3.5)^{\star}$ & & & & NA (NA, 7.5) & \\
\hline \multirow{2}{*}{ NH blacks } & $145.2(10.9,26.8)^{\star}$ & & & & $198.2(4.1,12.2)^{\star}$ & \\
\hline & $118.1(15.7,34.2)^{\star}$ & $240.5(5.5,18.9)^{\star}$ & $243.3(6.6,22.8)^{\star}$ & $312.5(4.8,19.8)^{\star}$ & $217.6(4.3,13.8)^{\star}$ & $170.6(3.7,10.1)^{\star}$ \\
\hline \multirow{2}{*}{$\mathrm{NH}$ whites } & $467.0(6.7,38.2)^{\star}$ & & & & $683.0(4.0,31.2)^{\star}$ & \\
\hline & $262.9(10.3,37.3)^{\star}$ & $754.2(4.7,40.3)^{\star}$ & $541.7(6.3,40.6)^{\star}$ & $643.9(4.3,31.6)^{\star}$ & $666.1(4.2,32.5)^{\star}$ & $685.0(3.7,29.2)^{\star}$ \\
\hline \multirow{2}{*}{ Hispanics } & $78.1(8.1,14.4)^{*}$ & & & & $104.7(6.3,12.9)^{\star}$ & \\
\hline & $58.7(9.0,14.2)^{\star}$ & $361.3(2.9,13.5)^{\star}$ & $58.1(10.2,16.0)^{\star}$ & $89.9(6.9,13.1)^{\star}$ & $63.4(8.2,13.4)^{*}$ & NA (UR, 12.0) \\
\hline \multicolumn{7}{|l|}{ Suicide } \\
\hline NH AIAN & $105.6(12.1,24.8)^{*}$ & & & & $75.9(19.5,34.4)^{\star}$ & \\
\hline $\mathrm{NH}$ API & $5.8(7.1,7.6)$ & & & & NA (UR, 14.9) & \\
\hline \multirow{2}{*}{ NH blacks } & $12.7(7.3,8.3)^{\star}$ & & & & $18.4(6.4,7.6)$ & \\
\hline & $3.5(7.9,8.2)$ & $25.2(6.1,7.7)$ & $29.6(7.0,9.0)^{*}$ & $9.0(8.4,9.2)$ & $49.4(6.0,8.9)$ & $-14.5(7.0,6.0)$ \\
\hline \multirow{2}{*}{ NH whites } & $46.3(15.4,22.5)^{\star}$ & & & & $62.7(16.8,27.3)^{\star}$ & \\
\hline & $29.4(15.9,20.5)^{\star}$ & $53.2(13.6,20.8)^{\star}$ & $57.0(16.3,25.6)^{\star}$ & $49.7(17.1,25.6)^{\star}$ & $61.8(16.5,26.7)^{\star}$ & $64.3(17.2,28.2)^{\star}$ \\
\hline \multirow{2}{*}{ Hispanics } & $23.7(6.8,8.3)^{\star}$ & & & & $6.7(11.8,12.6)$ & \\
\hline & $20.5(6.5,7.8)^{\star}$ & $41.6(5.4,7.6)^{\star}$ & $24.5(7.5,9.4)$ & $9.9(11.2,12.4)$ & $20.3(10.2,12.3)$ & $-12.7(15.1,13.2)$ \\
\hline
\end{tabular}

\section{${ }^{*} \mathrm{P}<0.05$.}

$\mathrm{NH}=$ non-Hispanic; $\mathrm{AlAN}=$ American Indians and Alaskan Natives; $\mathrm{API}=$ Asians and Pacific Islanders; $\mathrm{NA}=$ not applicable (data unavailable), no nadir occurred; UR=unreliable data ( $<20$ deaths from specified cause of death in given year, racial-ethnic group, and geographic setting);large central=metropolitan statistical areas (MSAs) of $\geq 1$ million population containing largest principal city; large fringe=MSAs of $\geq 1$ million population that do not qualify as large central metro counties; medium=MSAs with populations of 250000 -999 999 ; small metro=MSAs with populations $<250000$; micro=micropolitan statistical areas; non-core=counties that do not qualify as micropolitan.

in progress for many conditions: mortality rates that had been decreasing among populations of color reached a nadir, giving way to increasing death rates, often accelerating faster among non-white Americans than among whites. This is especially troubling given the historically high baseline mortality rates that exist among populations of color, notably non-Hispanic blacks and non-Hispanic American Indians and Alaskan Natives. ${ }^{2}$

Although mortality rates were higher among men than among women, the relative increase in fatal drug overdoses and suicides was greater among women, consistent with other reports of the worsening health disadvantage among women in the US. ${ }^{2122384445}$ Others have studied geographic patterns in US mortality trends. ${ }^{492146-49}$ Our study confirms reports ${ }^{11}$ of higher mortality rates and larger relative increases in mortality in rural areas, but it also documents statistically significant increases within metropolitan areas. NonHispanic whites and Hispanics experienced the largest proportional increases in drug overdose deaths in suburban fringe areas, whereas the largest increases among non-Hispanic blacks occurred in small cities. Non-Hispanic American Indians and Alaskan Natives living in metropolitan areas experienced a larger relative increase in suicides than those in rural areas.

\section{Limitations of this study}

This study's limitations deserve consideration. For example, comparisons of mortality rates for some racial groups are vulnerable to biases introduced by misclassification of race and undercounting. ${ }^{50}$ Funeral directors record race and Hispanic ethnicity based on descriptions from informants (eg, family members) or direct observation. ${ }^{51}$ Census data on race and ethnicity are based on self report. The data provided by CDC WONDER are unlinked and can therefore be influenced by numerator-denominator mismatching. For example, death rates can be biased by inconsistencies between vital statistics and census data in classifying race and Hispanic origin. ${ }^{52}$ Some of the large relative increases in mortality rates reported here involved uncommon causes of death. For example, the $242.0 \%$ increase in mortality from alcohol poisoning in non-Hispanic blacks reflected an absolute rate increase from 0.2 to 0.8 deaths per 100000 .

Although we tried to limit coding bias by restricting the analysis to the years (1999 and later) during which only ICD-10 coding was in effect, subtle changes in coding practices may still have influenced reported mortality rates. These influences could include new coding directives, changes in coding algorithms or software, and trends among professionals (eg, greater 
propensity to code Alzheimer's disease as a cause of death). Changes in the proportion of decedents undergoing autopsy, the propensity of medical examiners to assign socially stigmatized causes of death (eg, suicide, substance misuse), and disparities in these trends by geography or decedent race-ethnicity could also influence results.

In addition, the analysis omitted data before 1999, information that could help contextualize trends; excluded people younger and older than 25-64 years; did not disaggregate results for age groups between ages 25 and 64 years or aggregate deaths over multiple years to enhance statistical power; and stratified mortality rates only by race-ethnicity and not by education, income, or other factors that influence mortality. ${ }^{53-55}$ It is therefore unclear, for example, whether mortality rate increases differ as substantially by race-ethnicity among adults with a college education.

\section{Policy and research implications}

This report does not investigate why mortality is increasing, a major research challenge begun by others $^{56}$ but beyond the scope of this study. Our goal was to raise public awareness, in particular to present the evidence that the problem of increasing mortality rates is much larger than the opioid epidemic and affects more than one race. Death rates are increasing across the US population for dozens of conditions. Of particular urgency is recognizing that the unfavorable mortality pattern that began for some groups in the 1990s is now unfolding among Hispanics and non-Hispanic blacks, a development made more consequential by their high baseline mortality rates. That these increases are just becoming apparent provides a window of opportunity for early intervention. A chance exists to prevent expansion of this public health crisis through action by policy makers to deal with the social determinants of health, and by researchers to intensify investigation of the causes and solutions. We thank Lauren Snellings for her assistance in error checking the
text, tables, and figures.

Contributors: SHW led the preparation of the manuscript. He is the guarantor. JMB and KJB obtained the source data. DAC oversaw quantitative methods. Along with the other contributors, EBZ and SMB reviewed drafts and recommended editorial modifications. The corresponding author attests that all listed authors meet authorship criteria and that no others meeting the criteria have been omitted.

Funding: This study was unfunded. The methods used for this study were developed in prior research to examine mortality rates in the US white population. The prior studies were funded by the California Endowment, the Missouri Foundation for Health, and the Kansas Health Institute, but these funders protected the independence of the investigators and had no role in this study.

Competing interests: All authors have completed the ICMJE uniform disclosure form at www.icmje.org/coi_disclosure.pdf and declare: no support from any organization for the submitted work, no financial relationships with any organizations that might have an interest in the submitted work in the previous three years, and no other relationships or activities that could appear to have influenced the submitted work.

Ethical approval: Not required.

Data sharing: No additional data available.

Transparency: The manuscript's guarantor (SHW) affirms that the manuscript is an honest, accurate, and transparent account of the study, that no important aspects of the study have been omitted, and that any discrepancies from the study as originally planned have been explained.

This is an Open Access article distributed in accordance with the Creative Commons Attribution Non Commercial (CC BY-NC 4.0) license, which permits others to distribute, remix, adapt, build upon this work non-commercially, and license their derivative works on different terms, provided the original work is properly cited and the use is noncommercial. See: http://creativecommons.org/licenses/by-nc/4.0/.

1 Murphy SL, Xu J, Kochanek KD, Curtin SC, Arias E. Deaths: Final Data for 2015. Natl Vital Stat Rep 2017;66:1-75.

2 Kochanek KD, Murphy S, Xu J, Arias E. Mortality in the United States, 2016. NCHS Data Brief 2017;(293):1-8.

3 Case A, Deaton A. Rising morbidity and mortality in midlife among white non-Hispanic Americans in the 21st century. Proc Natl Acad Sci USA 2015;112:15078-83. doi:10.1073/pnas.1518393112

4 Squires D, Blumenthal D. Mortality Trends Among Working-Age Whites: The Untold Story. Issue Brief (Commonw Fund) 2016;3:1-11.

5 Kochanek KD, Murphy SL, Xu J, Tejada-Vera B. Deaths: Final Data for 2014. Natl Vital Stat Rep 2016;65:1-122.

6 Kochanek KD, Arias E, Bastian BA. The effect of changes in selected age-specific causes of death on non-Hispanic white life expectancy between 2000 and 2014. NCHS Data Brief 2016;(250):1-8.

7 Xu J, Murphy SL, Kochanek KD, Arias E. Mortality in the United States, 2015. NCHS Data Brief 2016;(267):1-8.

8 Shiels MS, Chernyavskiy P, Anderson WF, et al Trends in premature mortality in the USA by sex, race, and ethnicity from 1999 to 2014 : an analysis of death certificate data. Lancet 2017;389:1043-54. doi:10.1016/S0140-6736(17)30187-3

9 Case A, Deaton A. Mortality and morbidity in the $21^{\text {st }}$ century. Brookings Pap Econ Act 2017;2017:397-476. doi:10.1353/ eca.2017.0005

10 Masters RK, Tilstra AM, Simon DH. Explaining recent mortality trends among younger and middle-aged White Americans. Int J Epidemiol 2018;47:81-8. doi:10.1093/ije/dyx127

11 Stein EM, Gennuso KP, Ugboaja DC, Remington PL. The epidemic of despair among white Americans: trends in the leading causes of premature death, 1999-2015. Am J Public Health 2017;107:1541-7. doi:10.2105/AJPH.2017.303941

12 Khazan O. Middle-aged white Americans are dying of despair. Atlantic 2015. https://www.theatlantic.com/health/ archive/2015/11/boomers-deaths-pnas/413971/

13 Krugman P. Despair, American style. New York Times. November 9 2015. https://www.nytimes.com/2015/11/09/opinion/despairamerican-style.html Accessed March 20, 2018.

14 Cunningham TJ, Croft JB, Liu Y, Lu H, Eke PI, Giles WH. Vital signs: racial disparities in age-specific mortality among blacks or African Americans-United States, 1999-2015. MMWR Morb Mortal Wkly Rep 2017;66:444-56. doi:10.15585/mmwr.mm6617e1

15 Astone NM, Martin S, Aron L. Death Rates for US Women Ages 15 to 54: Some Unexpected Trends. Urban Institute, 2015.

16 Rudd RA, Seth P, David F, Scholl L. Increases in Drug and OpioidInvolved Overdose Deaths - United States, 2010-2015. MMWR Morb Mortal Wkly Rep 2016;65:1445-52. doi:10.15585/mmwr. mm655051e1

17 Hedegaard H, Warner M, Miniño AM. Drug overdose deaths in the United States, 1999-2015. NCHS Data Brief 2017;(273):1-8.

18 Shiels MS, Freedman ND, Thomas D, Berrington de Gonzalez A. Trends in U.S. drug overdose deaths in non-Hispanic black, Hispanic, and non-Hispanic white persons, 2000-2015. Ann Intern Med 2018;168:453-5.

19 Katz J, Goodnough A. The opioid crisis is getting worse, particularly for black Americans. New York Times. December 22, 2017. https:// www.nytimes.com/interactive/2017/12/22/upshot/opioid-deathsare-spreading-rapidly-into-black-america.html?_r=1 Accessed March 20, 2018.

20 Lopez G. The opioid epidemic has now reached black America: drug overdose deaths are skyrocketing among black Americans. Vox. December 22, 2017. https://www.vox.com/science-andhealth/2017/12/22/16808490/opioid-epidemic-black-white Accessed March 20, 2018.

21 Kindig DA, Cheng ER. Even as mortality fell in most US counties, female mortality nonetheless rose in 42.8 percent of counties from 1992 to 2006. Health Aff (Millwood) 2013;32:451-8. doi:10.1377| hlthaff.2011.0892

22 Montez IK, Zajacova A. Why is life expectancy declining among low-educated women in the United States?Am J Public Health 2014;104:e5-7. doi:10.2105/AJPH.2014.302146

23 Acciai F, Firebaugh G. Why did life expectancy decline in the United States in 2015? A gender-specific analysis. Soc Sci Med 2017;190:174-80. doi:10.1016/j.socscimed.2017.08.004

$24 \mathrm{McGreal}$ C. Financial despair, addiction and the rise of suicide in white America. The Guardian. February 2016. 
25 Achenbach J, Keating D. A new divide in American death: an urbanrural mortality gap emerges among whites as risky behaviors work to defy modern trends. Washington Post. April 10, 2016. http://www. washingtonpost.com/sf/national/2016/04/10/a-new-divide-inamerican-death/?utm_term=.749f27a370c4 Accessed March 20, 2018

26 Saslow E. 'We don't know why it came to this.' As white women between 25 and 55 die at spiking rates, a close look at one tragedy. Washington Post. April 8, 2016. http://www.washingtonpost.com/ sf/national/2016/04/08/we-dont-know-why-it-came-to-this/?utm_ term $=.858311 \mathrm{a} 81 \mathrm{c} 71$ Accessed March 20, 2018.

27 Centers for Disease Control and Prevention, National Center for Health Statistics. Underlying Cause of Death 1999-2016 on CDC WONDER Online Database, released December, 2017. http://wonder. cdc.gov/ucd-icd10.html Accessed February 26, 2018.

28 Centers for Disease Control and Prevention. Vital Statistics of United States, 1999, Mortality: Technical Appendix. Hyattsville, MD U.S. Department of Health and Human Services, 2004. Accessed June 24, 2018 at https://wonder.cdc.gov/wonder/help/CMF/ TechnicalAppendix1999.pdf

29 World Health Organization. The ICD-10 Classification of Mental and Behavioural Disorders: Clinical Descriptions and Diagnostic Guidelines. World Health Organization, 1992.

30 Joinpoint Regression Program, Version 4.6.0.0 - April 2018 Statistical Methodology and Applications Branch, Surveillance Research Program, National Cancer Institute.

31 Kim HJ, Fay MP, Feuer EJ, Midthune DN. Permutation tests for joinpoint regression with applications to cancer rates. Stat Med 2000;19:335-51.

32 Clegg LX, Hankey BF, Tiwari R, Feuer EJ, Edwards BK. Estimating average annual per cent change in trend analysis. Stat Med 2009;28:3670-82. doi:10.1002/sim.3733

33 U.S. Office of Management and Budget. Revisions to the Standards for the Classification of Federal Data on Race and Ethnicity. 62 FR 58782 Federal Register / Vol. 62, No. 210 / Thursday, October 30, 1997.

34 Ingram DD, Franco SJ. 2013 NCHS urban-rural classification scheme for counties. Vital Health Stat 2 2014;(166):1-73.

35 Hummer RA. Adult mortality differentials among Hispanic subgroups and non-Hispanic whites. Soc Sci Q 2000;81:459-76.

36 Velasco-Mondragon E, Jimenez A, Palladino-Davis AG, Davis D, Escamilla-Cejudo JA. Hispanic health in the USA: a scoping review of the literature[published online December 7, 2016]. Public Health Rev 2016;37:31. doi:10.1186/s40985-016-0043-2.

37 Woolf SH, Aron L. Failing health of the United States. BMJ 2018;360:k496. doi:10.1136/bmj.k496

38 Woolf SH, Aron L, eds. U.S. Health in International Perspective: Shorter Lives, Poorer Health. Panel on Understanding Cross-National Health Differences Among High-Income Countries. National Research Council, Committee on Population, Division of Behavioral and Social Sciences and Education, and Board on Population Health and Public Health Practice, Institute of Medicine. The National Academies Press, 2013

39 Woolf $\mathrm{SH}$, Aron LY The US health disadvantage relative to other high-income countries: findings from a National Research Council/ Institute of Medicine report. JAMA 2013;309:771-2. doi:10.1001/ jama.2013.91

40 Woolf SH. Progress in achieving health equity requires attention to root causes. Health Aff (Millwood) 2017;36:984-91. doi:10.1377/ hlthaff.2017.0197

41 Kolata G, Cohen S. Drug overdoses propel rise in mortality rates of young whites. New York Times. January 16, 2016. https://www. nytimes.com/2016/01/17/science/drug-overdoses-propel-rise-inmortality-rates-of-young-whites.html Accessed March 21, 2018
42 Douthat R. The dying of the whites. New York Times. November 9 , 2015. https://www.nytimes.com/2015/11/08/opinion/sunday/thedying-of-the-whites.html Accessed March 20, 2018

43 Achenbach J. No longer 'Mayberry': a small Ohio city fights an epidemic of self-destruction. Washington Post. December 29 , 2016. https://www.washingtonpost.com/national/health-science/ no-longer-mayberry-a-small-ohio-city-fights-an-epidemic-ofself-destruction/2016/12/29/a95076f2-9a01-11e6-b3c9f662adaa0048_story.html?utm_term=.91d0d25992d3 Accessed March 20, 2018

44 Montez JK, Zajacova A. Explaining the widening education gap in mortality among U.S. white women. J Health Soc Behav 2013;54:166-82. doi:10.1177/0022146513481230

45 Montez JK, Zajacova A, Hayward MD. Explaining inequalities in women's mortality between U.S. states. SSM Popul Health 2016;2:561-71. doi:10.1016/j.ssmph.2016.07.004

46 Ezzati M, Friedman AB, Kulkarni SC, Murray Cl. The reversal of fortunes: trends in county mortality and cross-county mortality disparities in the United States. PLoS Med 2008;5:e66. doi:10.1371/journal.pmed.0050066

47 Dwyer-Lindgren L, Bertozzi-Villa A, Stubbs RW, et al. Inequalities in life expectancy among US counties, 1980 to 2014: temporal trends and key drivers. JAMA Intern Med 2017;177:1003-11. doi:10.1001/ jamainternmed.2017.0918

48 Dwyer-Lindgren L, Bertozzi-Villa A, Stubbs RW, et al. Trends and patterns of geographic variation in mortality from substance use disorders and intentional injuries among US counties, 1980-2014. JAMA 2018;319:1013-23. doi:10.1001/jama.2018.0900

49 Mokdad AH, Ballestros K, Echko M, et al, US Burden of Disease Collaborators. The state of US health, 1990-2016: burden of diseases, injuries, and risk factors among US states. JAMA 2018:319:1444-72. doi:10.1001/jama.2018.0158

50 Arias E, Schauman WS, Eschbach K, Sorlie PD, Backlund E. The validity of race and Hispanic origin reporting on death certificates in the United States. Vital Health Stat 2 2008;2:1-23.

51 Centers for Disease Control and Prevention. Funeral Directors' Handbook on Death Registration and Fetal Death Reporting, 2003 revision. DHHS Publication No. 2005-1109. Hyattsville, MD: U.S Department of Health and Human Services, 2004. Accessed June 24 2018 at https://www.cdc.gov/nchs/data/misc/hb_fun.pdf

52 Rosenberg HM, Maurer JD, Sorlie PD,et al. Quality of death rates by race and Hispanic origin: a summary of current research, 1999. Vital Health Stat 2 1999;2:1-13.

53 Sasson I. Trends in life expectancy and lifespan variation by educational attainment: United States, 1990-2010. Demography 2016;53:269-93. doi:10.1007/s13524-015-0453-7

54 Chetty R, Stepner M, Abraham S,et al. The association between income and life expectancy in the United States, 2001-2014. JAMA 2016;315:1750-66. doi:10.1001/jama.2016.4226

55 Galea S, Tracy M, Hoggatt KJ, Dimaggio C, Karpati A Estimated deaths attributable to social factors in the United States. Am J Public Health 2011;101:1456-65. doi:10.2105/ AlPH.2010.300086

56 Preston SH, Vierboom YC, Stokes A. The role of obesity in exceptionally slow US mortality improvement. Proc Natl Acad Sci U S A 2018;115:957-61. doi:10.1073/pnas.1716802115

Web appendix: Supplementary materials 


\section{thelomj Visual summary 1 Why is US life expectancy falling behind?}
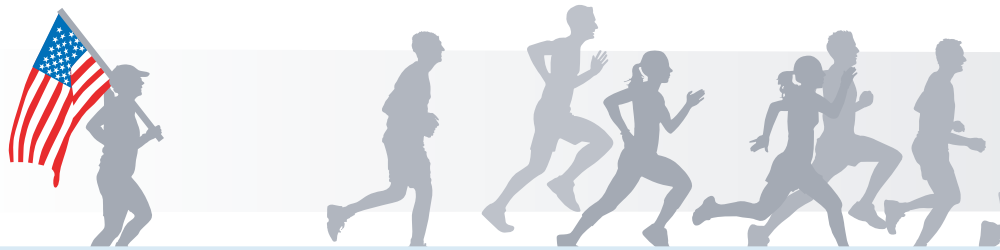

Coming in last

The United States now ranks near the bottom of life expectancy rankings, when compared to other high income countries. In a 2018 paper in The BMJ, authors Ho and Hendi compared life expectancy trends from 1990 to 2015 in 18 countries commonly used in cross national comparisons. These countries have all achieved high levels of development, and underwent changes in mortality associated with that development at roughly the same time. They also have large enough populations to produce reliable estimates of mortality.

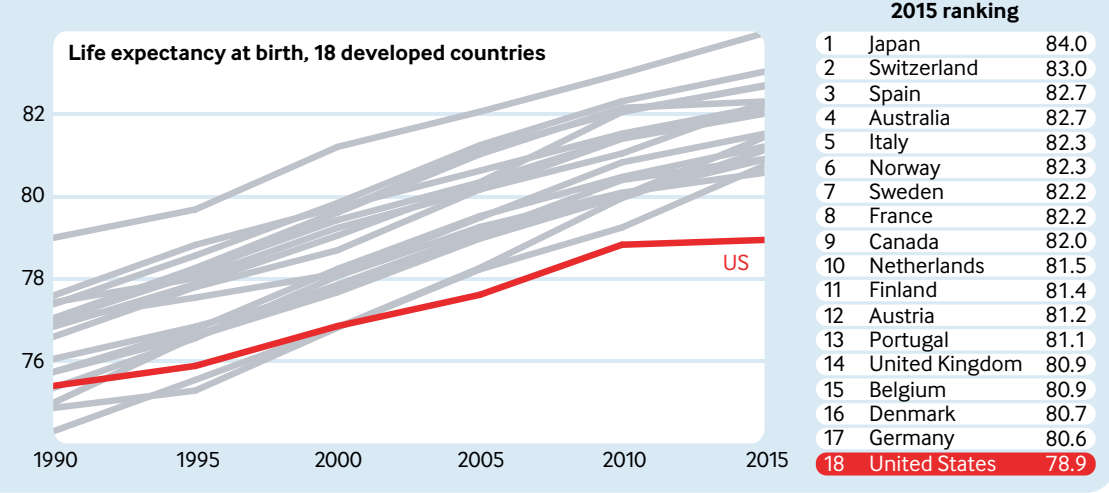

\section{Before their time}

$\mathrm{Ho}$ and Hendi observed recent widespread life expectancy declines across the 18 high income countries. The decline in most countries was concentrated at ages $\geq 65$, and mostly attributable to diseases related to a severe influenza season. However, the US decline was largely concentrated at younger ages, particularly those in their 20 s and 30 s, and attributable to external causes like drug overdose.

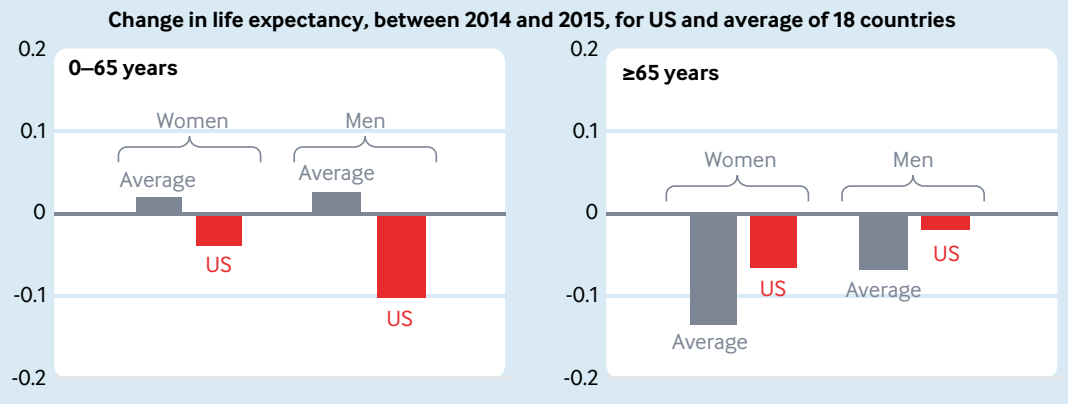

\section{Who is affected?}

Further detail is provided by Woolf et al, in their simultaneously published paper in The BMJ. They compared midlife mortality patterns in the US across racial and ethnic groups from 1999 to 2016. Among people aged 25-64 years, increases in mortality rates have been observed in all groups in recent years.

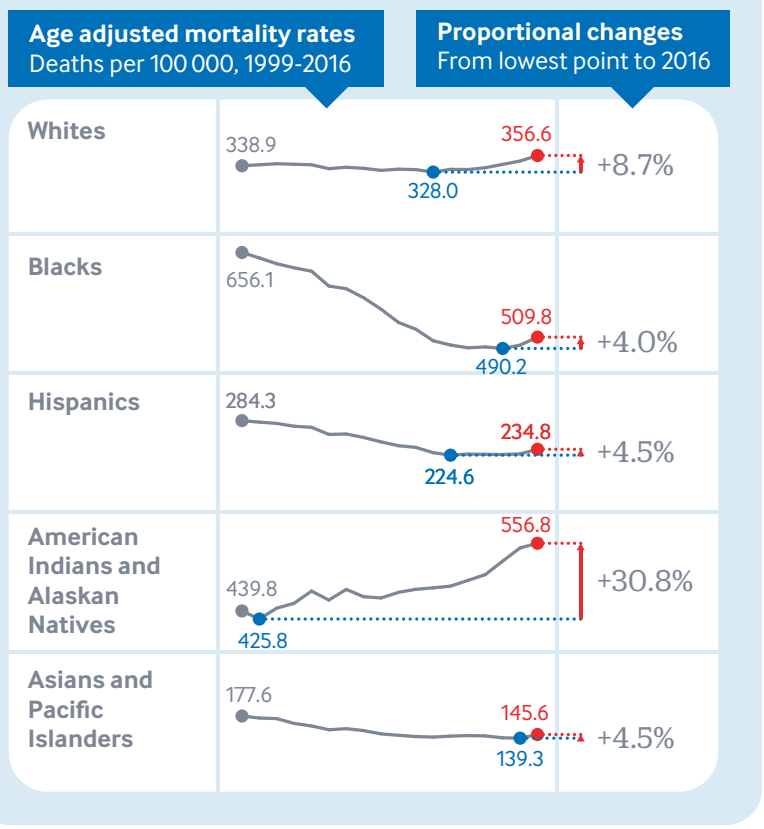

\section{Cause for concern}

Within these groups, there are a variety of different reasons for the observed changes in mortality. Changes were driven not only by external causes of death, but also by a variety of organ diseases and increases in mortality from mental and behavioral disorders.

\section{Top 3 causes of excess deaths 1999-2016}

External causes

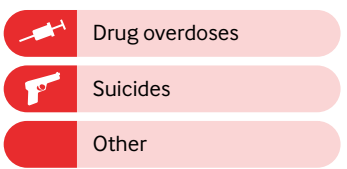

49606

Organ diseases

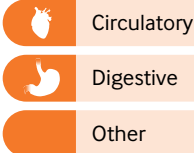

33431

Mental and behavioural

Involving psychoactive
substances
Organic

